\title{
Physical strength predicts political violence
}

Manuscript accepted for publication in Evolution and Human Behavior.

Changes might occur between this and the published version.

\section{Henrikas Bartusevičius ${ }^{1}$}

henrikas.bartusevicius@gmail.com

Department of Political Science, Aarhus University

Bartholins Allé 7, 8000 Aarhus C, Denmark

\section{Competing interests: None.}

\section{Declarations of interests: None.}

Funding: This research was supported by the Danish Council for Independent Research (Grant no. 4091-00206B) and the Innovation Fund Denmark (Grant No. 4110-00002B).

Role of the funding source: The funders did not influence the study design, the collection, analysis, and interpretation of data, the writing of the report, and the decision to submit the article for publication.

Acknowledgments: This research was part of a larger project on political violence involving Florian van Leeuwen and Michael Bang Petersen. Both have contributed to designing and conducting the surveys reported in the present paper. I also thank the participants of the $30^{\text {th }}$ annual meeting of the Human Behavior and Evolution Society, the internal seminar at the Department of Political Science at Aarhus University, and the Research on Online Political Hostility 2020 conference. I am particularly grateful to Alexander Bor, Florian van Leeuwen, and Michael Bang Petersen for insightful suggestions.

Word Count: 5,985.

\footnotetext{
${ }^{1}$ Present address (from 1 April 2021): Peace Research Institute Oslo, Hausmanns gate 3, 0186 Oslo, Norway.
} 


\begin{abstract}
Research has revealed an association between individual strength and attitudinal support for modern war. Physical strength of one individual has an infinitesimal effect on the outcomes of state-level aggression involving large-scale armies and complex military technology. The fact that stronger individuals do support such aggression hints at an evolved psychology specialized for small-scale coalitional aggression, where strength of coalition members non-negligibly contribute to the net coalition strength. Here, I examined whether strength also accounts for participation in modern political aggression, as contrasted to mere support. Given that contemporary political aggression primarily occurs within - not between - states, I focused on intra-state forms of political violence, specifically violent antigovernment protests. To enhance external and ecological validity, I relied on large probability samples from both non-WEIRD and WEIRD countries experiencing political violence $(\mathrm{N}=6,283$; interviewees were quota-sampled from YouGov online panels to generate representative samples of online adult populations). Multinational analyses revealed that strength significantly predicts intentions to participate in political violence and self-reported participation, and that this association is stronger among young interviewees, but not among men (compared to women). The predictive power of strength was modest but comparable to that of gender, an established predictor of aggression. I discuss why the fact that strength - a physiological variable - relates to political violence - a complex modern phenomenon - is remarkable. Subsequently, I suggest a new research agenda that draws on insights from evolutionary research to study modern political violence.
\end{abstract}

Keywords: formidability; strength; coalitional aggression; political violence; protest; WEIRD 


\section{Introduction}

Research has identified an association between formidability and aggression in men. Physical strength (proxied, for example, by body size, self-perceived strength, or weight lifting) predicts trait aggression, history of fighting, endorsement of aggression, and a range of other outcomes commonly associated with aggression, such as Social Dominance Orientation (Archer \& Thanzami, 2007, 2009; Gallup et al., 2007; Felson, 1996; Pellegrini et al., 2007; Petersen et al., 2013; Petersen \& Laustsen, 2019; Price et al., 2011; Raine et al., 1998; Sell et al., 2009; Tremblay, 1998). The relationship between strength and aggression appears to be causal (Petersen \& Dawes, 2017) and holds across diverse samples, including small-scale societies (Hess et al., 2010; von Rueden et al., 2008).

Intriguingly, research has also revealed an association between physical strength and attitudinal support for political aggression, such as interstate war (Sell et al., 2009, 2017; see also Price et al., 2012). The strength of one individual has virtually no effect on the outcomes of state-level aggression involving large-scale armies and complex military technology. The fact that stronger individuals do support such aggression hints at an evolved psychology specialized for small-scale coalitional aggression, where (i) fighting ability of coalition members can non-negligibly contribute to the net coalition strength, (ii) stronger individuals can claim a larger share of spoils, and (iii) stronger individuals have a higher likelihood of surviving combat (Sell et al., 2017). ${ }^{2}$ Drawing on this research, I examined whether strength also relates to participation in modern political aggression.

This report contributes to existing research in the following ways. First, extant studies have relied on attitudinal outcome measures, specifically support for or endorsement of political aggression. Here, I analyzed behavioral intentions to participate and behavioral

\footnotetext{
${ }^{2}$ Note that the form, intensity, and even the existence of coalitional aggression or war in human evolutionary past remains debated (e.g., Fry, 2015).
} 
self-reports of actual participation in political aggression. Endorsement of coalitional aggression is likely an output of the same psychology that regulates participation in coalitional aggression. Hence, the extent to which people favor coalitional aggression potentially corresponds to their willingness to engage in it. Still, focusing explicitly on participation more closely corresponds to the theoretical arguments presented by Sell et al. (2017). If stronger individuals had a higher chance of surviving ancestral inter-group combat, received larger shares of spoils, and non-negligibly contributed to victories, then selection should have favored psychological mechanisms that motivate stronger individuals to engage in coalitional aggression. ${ }^{3}$

Second, existing research has focused on one category of political aggression: armed conflicts between states. Today, most political aggression occurs within states. For example, in 2019 the Uppsala Conflict Data Program recorded 54 armed conflicts that involved states; of these, only two were directly fought between states - the rest were primarily fought between non-state actors, such as rebel organizations, and states (Pettersson \& Öberg 2020). ${ }^{4}$ To assess the role of strength in the most prevalent forms of contemporary political aggression, I focused on intra-state forms of political violence, specifically violent antigovernment protests.

Third, existing studies have largely relied on undergraduate samples. Some research suggests that the strength-aggression association may only hold among undergraduate-aged

\footnotetext{
${ }^{3}$ In fact, endorsing coalitional aggression, and not engaging in it, may have been adaptive for physically weaker individuals, for example, if aggression resulted in access to resources for all members of the larger group, including those who do not engage in aggression. Following this logic, women, compared to men, should be less motivated to engage in-but no less supportive of - coalitional aggression.

${ }^{4}$ Although, $40 \%$ of these intra-state armed conflicts saw involvement of external states in the form of military support (Pettersson \& Öberg 2020).
} 
populations (Price et al., 2012). To assess whether the strength-aggression link exists in the general population, and whether it interacts with age, I analyzed large nationally representatives samples. To enhance external validity, I relied on samples from both Western, educated, industrialized, rich, and democratic (WEIRD) and non-WEIRD countries: South Africa, Venezuela, Nicaragua, and the United States.

Finally, understanding the dynamics of modern political violence is extremely cognitively demanding, especially for individuals who have no direct experience with it. Therefore, I sampled from populations that were experiencing political violence. I assumed that such samples would have a more realistic grasp of costs and benefits involved in contemporary political violence, ${ }^{5}$ and hence report realistic behavioral intentions. I also expected these samples to contain individuals who have actually engaged in political violence.

\subsection{Hypotheses}

First, I tested the general hypothesis that strength relates to political violence (H1). Subsequently, corresponding to prior studies (Price et al., 2012; Sell et al., 2009; 2017), I tested whether the strength-political violence association is stronger among men (H2) and young interviewees (H3). H2 draws on the claim that ancestral coalitional aggression was a men activity, and hence that the aggression-regulating mechanisms - that track physical strength-were selected in men (Sell et al., 2009; 2017). H3 draws on research by Price et al. (2012), who found that the strength-aggression association was stronger among younger participants in their sample. Men aggression peaks around undergraduate age years (Daly \& Wilson, 1988). As aggression tappers with age, so may the strength-aggression association (Price et al., 2012). With age, men may also increasingly rely on prestige or expertise, rather than strength, to pursue social status, which may also diminish the strength-aggression association among older men.

\footnotetext{
${ }^{5}$ Compared, for example, to undergraduate samples in countries free of political violence.
} 


\section{Materials and Methods}

\subsection{Samples}

This research was part of a larger project on political violence that conducted surveys in multiple countries ([references redacted for peer review]). The first survey was conducted in South Africa $(\mathrm{N}=2,170)$, a country with one of the Africa's highest annual incidence of protests, some of which involve violence (Salehyan et al., 2012). Subsequently, data was collected in Venezuela $(\mathrm{N}=1,000)$. Five months prior to the survey, up to six million people (roughly $20 \%$ of the population) reportedly participated in the nation-wide Mother of All Marches (Gleditsch, 2020). This, preceding, and subsequent protests generated hundreds of deaths and thousands injured. Next, data was collected in Nicaragua $(\mathrm{N}=1,574)$, which also experienced large-scale protests during the survey, with hundreds of thousands of participants, hundreds of deaths and thousands injured. Finally, a survey was conducted in the United States $(\mathrm{N}=1,539)$, a paradigmatic WEIRD country. No major events of political violence took place in the US during the survey. However, the US has a high overall incidence of protest events, some of which involve violence (Beyerlein et al., 2018; Kishi \& Jones, 2020).

The surveys in South Africa and the US were administered in English in October 2017 and 2019, respectively. The surveys in Venezuela and Nicaragua were administered in Spanish in September 2017 and October 2018. All surveys were conducted online by the survey agency YouGov, and quota-sampled for age, gender, and geography to obtain nationally representative samples of adult online populations. No data exclusions were performed. Don't know and prefer not to state were coded as missing observations.

The surveys complied with [redacted for peer review] University's Code of Conduct as well as the Committee Act of the [redacted for peer review] National Committee of Health Research Ethics, which states that "Surveys using questionnaires and interviews that do not involve human biological material (section 14(2) of the Committee Act)" are exempted from approval. Informed consent was obtained from all interviewees. 


\subsection{Outcomes}

I relied on two outcome measures. First, I used a standardized question about participation in political violence over the last year from the Global Barometer Surveys: "Here is a list of actions that people sometimes take as citizens. For each of these, please tell me whether you, personally, have done any of these things during the past year. If not, would you do this if you had the chance: Used force or violence for a political cause?" ${ }^{6}$ Reply options were: no, would never do this $=0$; no, but would do if had the chance $=1$; yes, once or twice $=2 ;$ yes, several times $=3$; and yes, often $=4$ (the integers after the equality signs represent coding values). The item on political violence followed another item: "Attended a demonstration or a protest march". Hence, the question about political violence refers to participation in a protest-like violent antigovernment action. $65(3.00 \%)$ in South Africa, $45(4.50 \%)$ in Venezuela, $28(1.78 \%)$ in Nicaragua, and $111(7.29 \%)$ in the US reported participation in violence at least once during the past year. 124 (5.71\%), $174(17.40 \%), 111$ (7.05\%), and $95(6.17 \%)$, respectively, reported intentions to participate in violence if they had the chance.

Second, I obtained the 4-item Radicalism Intention Scale (RIS) (Moskalenko \& McCauley, 2009), reflecting behavioral intentions to engage in political violence at the time of interview: (i) "I would continue to support an organization that fights for my group's political and legal rights even if the organization sometimes breaks the law"; (ii) "I would continue to support an organization that fights for my group's political and legal rights even if the organization sometimes resorts to violence"; (iii) "I would participate in a public protest against oppression of my group even if I thought the protest might turn violent"; (iv) "I would attack police or security forces if I saw them beating members of my group". Interviewees indicated agreement with the four statements on a 7-point scale ranging from

\footnotetext{
${ }^{6}$ The formulations slightly differ across the Global Barometer Surveys. The quoted formulation is from Afrobarometer Round 5 (2015).
} 
strongly disagree $=0$ to strongly agree $=6$. Across the four samples, Cronbach's $\alpha$ s ranged from .80 to .86. Mean RIS in South Africa was 1.31, in Venezuela 1.91, in Nicaragua 1.33, and the US 1.59. Stated intentions predict actual behavior (Sheeran, 2002), including participation in protests (van Zomeren et al., 2008) and armed civil conflicts (Gómez et al., 2017).

The surveys measured a number of other outcomes related to political violence. These measures focused either on other types/measures of aggression (e.g., trait aggression or general militancy) or followed experimental vignettes that aimed to assess other research questions. I present analyses of these other outcomes in the Supplemental Material (SM) online (see Section S4), which produced estimates consistent with the main results reported below.

\subsection{Predictors}

Physical strength was measured with a self-perception measure introduced by Sell et al. (2009): "Please compare yourself to other people from your sex. How physically strong are you compared to other people from your sex?" Interviewees indicated their strength on an 11-point scale: I am stronger than $0 \%$ of other men/women $=0, I$ am stronger than $10 \%$ of other men/women $=10, \ldots, I$ am stronger than $100 \%$ of other men $/$ women $=100 . \mathrm{I}$ measured perceptions, because (i) the motivation to engage in violence may be a function of how strong one believes is rather than how strong one actually is, (ii) subjective measures allow reaching larger samples in relevant countries, and (iii) perceived and actual strength correlate - in Sell et al. (2009) sample, perceived strength correlated with weight lifting at $r=0.66$. See Section S1 in the SM for descriptive statistics and Section S2 in the SM for bivariate correlations for all predictor and outcome measures. 


\subsection{Modelling}

For comparability to prior studies (Price et al., 2012; Sell et al., 2009; 2017), I first conducted bivariate analyses. Subsequently, to assess potential confounding and compare the predictive power of strength, I conducted a multivariate analysis with a basic set of controls: gender $($ women $=0$, men $=1)$, age $(13$ categories, ranging from 18-22 to 80+, coded 1 to 13) ${ }^{7}$ education (four categories, from no or incomplete secondary $=0$ to complete tertiary $=3),{ }^{8}$ and subjective socioeconomic status (SES), measured with the Subjective Social Status Scale (Operario et al., 2004). Since the four surveys used identical predictor and outcome measures, I pooled the samples into one multinational dataset for the main analysis. Country-specific tests are also reported. Bivariate and multivariate analyses relied on OLS (for continuous outcomes) and logit (for binary outcomes) estimators. I also specified the so-called country-level "fixed effects" (McNeish \& Kelley, 2019), which partition between-country effects from within-country effects, i.e., remove confounding by country-level characteristics. Specifying country-level fixed effects is equivalent to country-level demeaning in the conventional multilevel framework (Bell et al., 2019). To aid interpretation of regression coefficients, all predictors and outcomes were normalized to range from 0 to 1 . The average predicted probabilities reported in Table 1 (Panel C) and the discussion section

${ }^{7}$ The surveys in South Africa, Venezuela, and Nicaragua asked interviewees to indicate particular age years. However, the US survey asked interviewees to indicate their age using 13 categories from $18-22$ to $80+$. To pool the four datasets into one for the multinational analyses, and for the sake of comparability across countries, I recoded particular age years in the South Africa, Venezuela, and Nicaragua samples using the age categories from the US survey.

${ }^{8}$ Different countries use different educational categories. Therefore, I generated four aggregate categories: no or incomplete secondary (i.e., no or incomplete high school); complete secondary; some tertiary (i.e., incomplete university or college); and complete tertiary. 
were calculated using the margins post-estimation command in Stata (version 15.1). The interactions reported in Figure 2 were generated using the interflex package in Stata (Hainmueller et al. 2019).

\subsection{Replication data}

The data files, command script, and original survey questionnaires are publically available on the Open Science Framework (OSF) repository:

https://osf.io/y8gfk/?view only=09e3d35469784ac4824fc06f9d0fc32d

\section{Results}

Does strength predict participation in political violence? In the multinational sample, strength was positively and significantly associated with self-reported participation in political violence, $b$ (unstandardized regression coefficient) $=0.036,95 \% \mathrm{CI}=[0.019,0.054]$ $(p<0.001)$, and intentions to engage in political violence (indexed with the Radicalism Intention Scale, RIS $), b=0.052,95 \% \mathrm{CI}=[0.022,0.081](p=0.001)$. All tests here and below are two-tailed. The association between strength and participation in political violence in South Africa was $b=0.040,95 \% \mathrm{CI}=[0.014,0.066](p=0.002)$, in Venezuela $b$ $=0.024,95 \% \mathrm{CI}=[-0.022,0.070](p=0.299)$, in Nicaragua $b=0.025,95 \% \mathrm{CI}=[-0.001$, 0.050] $(p=0.060)$, and in the US $b=0.052,95 \% \mathrm{CI}=[0.005,0.100](p=0.031)$. The association between strength and RIS in South Africa was $b=0.098,95 \% \mathrm{CI}=[0.048$, 0.147] $(p<0.001)$, in Venezuela $b=0.002,95 \% \mathrm{CI}=[-0.074,0.078](p=0.962)$, in Nicaragua $b=0.038,95 \% \mathrm{CI}=[-0.021, .097](p=0.204)$, and in the US $b=0.039,95 \% \mathrm{CI}=$ $[-0.022, .099](p=0.210)$. Hence, in some models, the coefficient of strength is above conventional significance thresholds. Furthermore, in all four samples, and the pooled sample, the coefficient is small (although comparable to those of other predictors; see below). This 
suggests that considerable sample size may be required to detect the strength-political violence association, and that some country-level characteristics potentially moderate this individual-level association. I return to these points in the discussion section.

Does strength predict political violence when controlling for a basic set of variables? As shown in Table 1, the coefficient of strength remained positive and significant in all models with the basic set of controls.

How does the predictive power of strength compare to that of other predictors? As shown in Panel A (Table 1), the coefficient of strength was larger than that of gender (Model 1). When regressed on RIS, the coefficient of strength was slightly smaller than that of gender (Panel B, Model 4). To grasp the substantive meaning of these comparisons, I also analyzed a dichotomized version of the behavioral self-report using a logit estimator: did not participate in political violence $=0$, participated in political violence $=1$ (Panel C). An individual scoring a maximum value on strength, compared to an individual scoring a mininimum value, was nearly three times more likely to report participation in political violence, average predicted probabilities $=2.7 \%$ and $7.5 \%$, respectively. Analogous probabilities for women and men were, respectively, $3.7 \%$ and $5.5 \%$. 
TABLE 1. Intentions to participate and self-reported participation in political violence as a function of physical strength

\begin{tabular}{|c|c|c|c|c|c|c|}
\hline \multicolumn{7}{|c|}{ A. Participation in political violence } \\
\hline & \multirow{3}{*}{\multicolumn{2}{|c|}{$\begin{array}{c}(1) \\
\text { Combined } \\
\mathrm{N}=4,858\end{array}$}} & \multicolumn{2}{|c|}{$(2)$} & \multicolumn{2}{|c|}{ (3) } \\
\hline & & & \multicolumn{2}{|c|}{ Men } & \multicolumn{2}{|c|}{ Women } \\
\hline & & & \multicolumn{2}{|c|}{$\mathrm{N}=2,570$} & \multicolumn{2}{|c|}{$\mathrm{N}=2,288$} \\
\hline & \multicolumn{2}{|r|}{$95 \% \mathrm{CI}$} & $b$ & $95 \% \mathrm{CI}$ & \multirow{3}{*}{$\frac{b}{0.039}$} & $95 \%$ CI \\
\hline Strength & 0.034 & $0.016,0.052$ & \multirow[t]{2}{*}{0.032} & $0.005,0.059$ & & \multirow[t]{2}{*}{$0.015,0.062$} \\
\hline Gender & 0.024 & $0.015,0.033$ & & & & \\
\hline Age & -0.119 & $-0.138,-0.099$ & -0.121 & $-0.149,-0.093$ & -0.116 & $-0.141,-0.090$ \\
\hline Education & -0.001 & $-0.016,0.014$ & -0.002 & $-0.024,0.020$ & 0.002 & $-0.018,0.022$ \\
\hline Subjective SES & 0.046 & $0.024,0.068$ & 0.072 & $0.040,0.104$ & 0.013 & $-0.016,0.041$ \\
\hline \multicolumn{7}{|c|}{ B. Radicalism intentions (RIS) } \\
\hline & \multirow{3}{*}{\multicolumn{2}{|c|}{$\begin{array}{c}(4) \\
\text { Combined } \\
\mathrm{N}=4,899\end{array}$}} & \multicolumn{2}{|c|}{$(5)$} & \multicolumn{2}{|c|}{$(6)$} \\
\hline & & & \multicolumn{2}{|c|}{ Men } & \multicolumn{2}{|c|}{ Women } \\
\hline & & & \multicolumn{2}{|c|}{$\mathrm{N}=2,601$} & \multicolumn{2}{|c|}{$\mathrm{N}=2,298$} \\
\hline & $b$ & $95 \%$ CI & $b$ & $95 \% \mathrm{CI}$ & $b$ & $95 \% \mathrm{CI}$ \\
\hline Strength & 0.048 & $0.019,0.078$ & 0.048 & $0.006,0.091$ & 0.055 & $0.013,0.096$ \\
\hline Gender & 0.057 & $0.042,0.072$ & & & & \\
\hline Age & -0.228 & $-0.259,-0.196$ & -0.216 & $-0.261,-0.172$ & -0.244 & $-0.288,-0.199$ \\
\hline Education & 0.024 & $-0.001,0.049$ & 0.025 & $-0.010,0.060$ & 0.018 & $-0.018,0.053$ \\
\hline Subjective SES & 0.030 & $-0.006,0.066$ & 0.028 & $-0.023,0.080$ & 0.025 & $-0.025,0.076$ \\
\hline \multicolumn{7}{|c|}{ C. Participation in political violence (binary) } \\
\hline \multicolumn{7}{|c|}{$(7)$} \\
\hline \multirow{2}{*}{\multicolumn{7}{|c|}{$\begin{array}{l}\text { Combined } \\
\mathrm{N}=4,858\end{array}$}} \\
\hline \multirow{2}{*}{\multicolumn{2}{|c|}{$\log$-odds }} & & & & & \\
\hline & & $95 \% \mathrm{CI}$ & $\begin{array}{l}\text { Probability of participation } \\
\text { when predictor value }=\text { min }\end{array}$ & \multicolumn{2}{|c|}{$\begin{array}{l}\text { Probability of participation } \\
\text { when predictor value }=\max \end{array}$} & Difference \\
\hline Strength & 1.138 & $0.581,1.695$ & $2.7 \%$ & & & $4.8 \%$ \\
\hline Gender & 0.439 & $0.152,0.725$ & $3.7 \%$ & & & $1.8 \%$ \\
\hline Age & -3.458 & $-4.164,-2.752$ & $10.9 \%$ & & & $-10.5 \%$ \\
\hline Education & 0.075 & $-0.377,0.527$ & $4.4 \%$ & & & $0.3 \%$ \\
\hline Subj. SES & 1.325 & $0.679,1.971$ & $2.4 \%$ & & & $5.6 \%$ \\
\hline
\end{tabular}


Is the strength-political violence association stronger among men? For comparability to prior studies (Price et al., 2012; Sell et al., 2009; 2017), I first analyzed the association between strength and self-reported participation in political violence in the sub-samples of men and women. The specifications here and below do not include control variables. As shown in Figure 1, the point estimate associated with strength was slightly larger in the men sub-sample, compared to the women sub-sample. The point estimate associated with RIS was also slightly larger in the men sub-sample than in the women sub-sample.
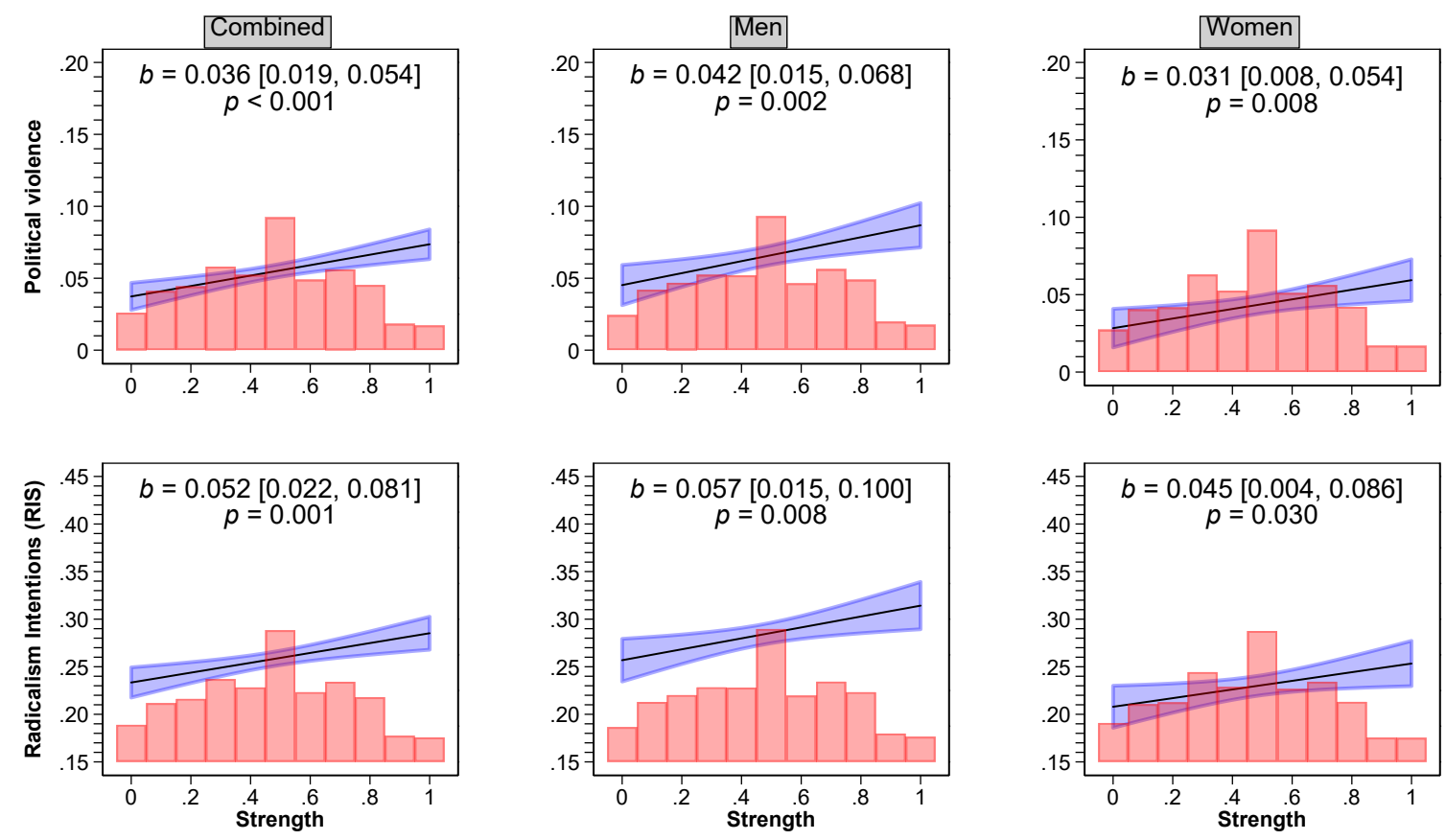

FIGURE 1. Predicted values of self-reported participation in political violence (upper row) and behavioral intentions to participate in political violence (indexed with the Radicalism Intention Scale, RIS). Predictors and outcomes are normalized to range from 0 to 1. The upper parts of graphs also report unstandardized regression coefficients with 95\% CIs in brackets and p-values below. All tests are two-tailed. The bars represent histograms of strength. 
Subsequently, I analyzed a multiplicative interaction term (strength*gender) using the complete dataset. In the multinational sample, gender did not significantly moderate the association of strength with participation in political violence, $b=0.014,95 \%$ $\mathrm{CI}=[-0.021,0.048](p=0.443)$ and RIS, $b=0.026,95 \% \mathrm{CI}=[-0.032,0.084](p=$ 0.375). Country-specific analyses produced similar estimates, with no significant interactions in any of the four samples and for both outcomes. In the model of participation in political violence, the strength*gender interaction in South Africa was $b=-0.006$, $95 \% \mathrm{CI}=[-0.057, .046](p=0.834)$, in Venezuela $b=.082,95 \% \mathrm{CI}=[-0.009,0.173](p$ $=0.078)$, in Nicaragua $b=.031,95 \% \mathrm{CI}=[-0.023,0.085](p=0.264)$, and in the US $b$ $=-0.026,95 \% \mathrm{CI}=[-0.121,0.069](p=0.592)$. In the model of RIS, the strength*gender interaction in South Africa was $b=0.023,95 \%$ CI $=[-0.075,0.122](p=0.642)$, in Venezuela $b=0.134,95 \%$ CI $=[-0.017,0.285](p=0.082)$, in Nicaragua $b=-0.071$, $95 \% \mathrm{CI}=[-0.195,0.054](p=0.265)$, and in the US $b=0.014,95 \% \mathrm{CI}=[-0.106,0.134]$ $(p=0.819)$

Is the strength-political violence association stronger among the young? In the multinational sample, age significantly moderated the association of strength with selfreported participation in political violence, $b=-0.116,95 \% \mathrm{CI}=[-0.185,-0.047](p=$ 0.001 ) and intentions to participate in political violence (RIS), $b=-0.121,95 \% \mathrm{CI}=[-$ 0.236, -0.006] $(p=0.039)$. Similar to the main strength-political violence association, country-specific analyses revealed between-country heterogeneity in the strength*age interactions. In the model of participation in political violence, the strength*age interaction in South Africa was $b=-0.069,95 \%$ CI $=[-0.174,0.035](p=0.194)$, in Venezuela $b=-0.185,95 \%$ CI $=[-0.393,0.024](p=0.082)$, in Nicaragua $b=0.016,95 \%$ CI $=[-$ $0.166,0.198](p=0.865)$, and in the US $b=-0.302,95 \% \mathrm{CI}=[-0.460,-.145](p<0.001)$. In the model of RIS, the strength*age interaction in South Africa was $b=-0.169,95 \%$ 
$\mathrm{CI}=[-0.367,0.029](p=0.095)$, in Venezuela $b=-0.041,95 \% \mathrm{CI}=[-0.388,0.306](p=$ 0.818), in Nicaragua $b=-0.153,95 \%$ CI $=[-0.558,0.253](p=0.461)$, and in the US $b$ $=-0.188,95 \% \mathrm{CI}=[-0.384, .007](p=0.059)$.

The theoretical arguments underlying H3 suggest that the strength*age interaction is driven by men. For example, young men, but not young women (or less so), may rely more on physical strength to pursue social status, which should increase the strength-aggression association among young men, but not (or less so) among young women (see also Price et al. 2012). If this is true, then we should only observe a significant strength*age interaction in the men sub-sample, or the interaction should be significantly stronger in the men sub-sample, compared to the women sub-sample. Contrary to this expectation, the model of participation in political violence (multinational sample) revealed that the point estimate associated with the strength*age interaction was larger in the women sub-sample, $b=-0.136,95 \% \mathrm{CI}=[-0.228,-0.045](p=0.004)$ vs. $b$ $=-0.084,95 \% \mathrm{CI}=[-0.186,0.019](p=0.110)$. The model of RIS (multinational sample) also revealed that the point estimate associated with the strength*age interaction was larger in the women sub-sample, $b=-0.172,95 \% \mathrm{CI}=[-0.332,-0.011](p=0.036)$ vs. $b$ $=-0.039,95 \% \mathrm{CI}=[-0.203, .124](p=0.636)$. Three-way interactions (strength*age*gender) estimated on the complete data were insignificant: $p=0.562$ in the model of participation in political violence and $p=0.424$ in the model of RIS.

The above analyses assumed linear interactions effects, i.e., that the strengthpolitical violence association changes at a constant rate with age. ${ }^{9}$ However, there is no

\footnotetext{
${ }^{9}$ Specifically, the assumption states that as the moderator (in this case, age) increases by one unit, the effect of the predictor (strength) on the outcome (political violence)
} 
a priori theoretical reason for this to be the case, and empirical research suggests that the linear interaction effect assumption often fails (Hainmueller et al., 2019). Therefore, I also explored non-linear interactions. Specifically, using a binning estimator (Hainmueller et al., 2019), I computed the marginal "effect" 10 of strength on the two outcomes for each of the 12 age categories (13th age category, $80+$, was removed from these analyses because of very few observations; see the density of age in Figure 2). As shown in Figure 2, the marginal effect of strength on participation in political violence was largest for the first three age categories, i.e., 18-22, 23-27, and 28-32. The analysis of RIS revealed a similar pattern; although, for the first age category, the lower CI of the marginal effect overlaps with zero. Importantly, for both outcomes, the marginal effect of strength reaches zero at age 38-42, and then remains either close to or below zero (or the $95 \%$ CIs considerably overlap with zero).

changes by $b$, and this change is constant across all predictor values (Hainmueller et al. 2019).

${ }^{10}$ Here, following conventions, I use the term "marginal effect"; however, since I randomized neither the predictor nor the moderator, these estimates should be interpreted as representing associations, not causal effects. 

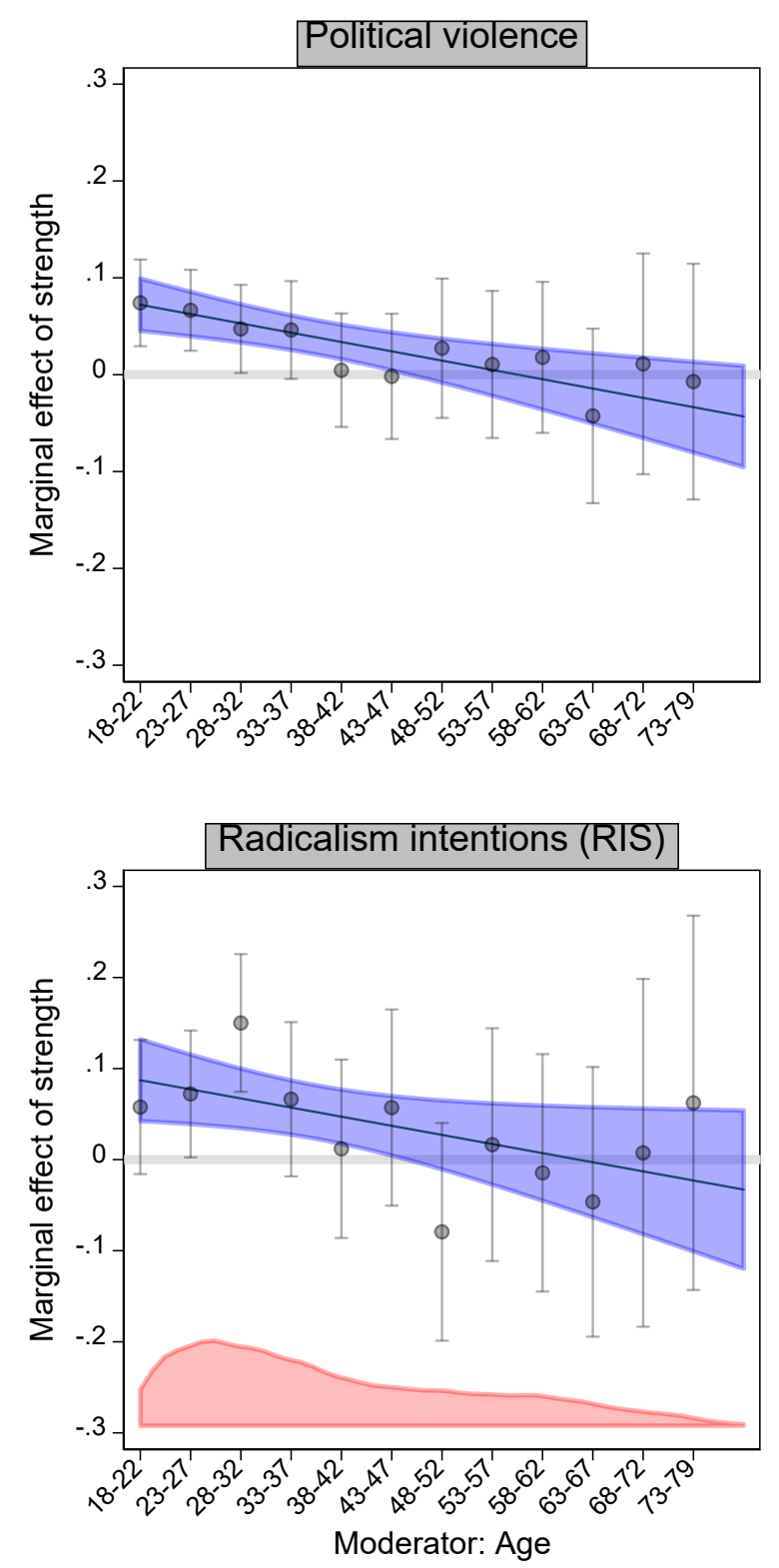

FiGURE 2. Marginal effects of strength on self-reported participation in political violence and behavioral intentions to participate in political violence (indexed with the Radicalism Intention Scale, RIS) for different age categories. The graphs depict estimates of the marginal effects of strength with the $95 \%$ CIs from the binning estimator (represented by dots with vertical bars), superimposed by estimates of the marginal effects of strength with the $95 \%$ CIs from the standard linear interaction model (diagonal lines with shaded areas). The shaded area at the lower part of the lower graph represents the density of age. 
Overall, the binning estimator produced estimates that correspond to those of the conventional linear interaction model, represented by the diagonal line/area superimposed on the binning estimates in Figure 2. Indeed, Wald tests failed to reject the null that the linear interaction model and the 12-bin model are statistically equivalent $(p \mathrm{~s}=$ 0.132 and 0.630$)$. Hence, these tests suggest that the linear interaction effect assumption is plausible in this case. When the linearity assumption holds, a standard linear interaction model is preferable to the binning model due to higher efficiency (i.e., the linear interaction model produces more precise estimates of marginal effects) (Hainmueller et al. 2019). The linear model thus suggests that the strength-political violence association is strongest at the youngest age and then gradually decreases, potentially reaching zero around the age of 47 . Note that the estimates are less precise for the lowest and the highest age categories. In the SM (Section S3), I also report analogous analyses of interactions for the sub-samples of men and women.

\section{Discussion}

Political violence is a major contributor to human mortality and suffering around the world (e.g., Ghobarah et al., 2003). The question of what causes such violence is thus a major concern among scholars, policy makers, and ordinary citizens. The current report presents evidence that physical strength predicts people's intentions to participate in political violence and self-reported participation. This evidence is consistent with the claim that engagement in contemporary political violence is regulated, at least in part, by a psychology specialized to small-scale coalitional aggression, which takes physical strength as an input variable into computations preceding violence (Sell et al., 2009, 2017). However, in partial contrast to previous research (see 4.1), I found little empirical support for the claim that physical strength more strongly relates to political violence 
among men, compared to women. Subsequently, and in line with previous research, I found evidence that strength plays a more prominent role in political violence among the young.

These results are also consistent with explanations that do not invoke adaptations to small-scale coalitional aggression. For example, the fact that stronger individuals are more prone to political violence may reflect their propensity to risk-taking or aggression, more generally, irrespective of whether it takes dyadic or coalitional forms. Adjudicating between alternative explanations was not my primary goal, however. I aimed, instead, to test whether strength - an established predictor of dyadic aggression - also predicts participation in contemporary intra-state political violence.

The predictive power of strength appears comparable to that of gender-another established predictor of aggression. Still, in comparison to some other variables, the coefficient associated with strength is small. For example, in the South Africa survey we also measured interviewees' political orientations ([reference redacted for peer review]). We found that an autocratic political orientation predicted Radicalism Intention Scale (RIS) at $b=0.36,(p<0.001)$ - a point estimate nearly four times larger than that of strength. This, however, should not surprise: political violence involves incompatibilities over complex political issues (e.g., the form of state governance or particular nationallevel policies), and hence it seems natural that people's orientations toward these issues play a more major role in their motivations to engage in political violence. What is more striking is that strength - a physiological characteristic - plays a non-negligible role in such complex motivations. Conventional explanations of political violence stress nuanced political, economic, cultural, and environmental factors (Dixon, 2009), often overlooking elemental individual characteristics. Here, I found that one such characteristic is a significant predictor of political violence. 
The substantive significance of the estimates associated with individual characteristics becomes clearer when we considered them in combination. For example, as reported above, an individual scoring a minimum value on self-perceived strength has an average predicted probability of participating (or self-reporting participation) in political violence of $2.7 \%$, and an analogous probability for an individual scoring a maximum value is $7.5 \%$. This probability increases to $16.9 \%$ for an individual who both scores a maximum value on strength and is of age between 18 and 22. The probability further increases to $19.6 \%$ for an individual who scores a maximum value on strength, is of age between 18 and 22, and is a man. These are substantively meaningful estimates, suggesting that just by focusing on the basic set of individual differences, one can account for a considerable share of variation in participation in contemporary political violence.

\subsection{Limitations}

First, I relied on non-experimental survey data. Hence, I cannot rule out the possibility that the strength-political violence link is reversed (e.g., participation in violence may motivate people to become physically stronger). However, longitudinal twin studies suggest that the causal direction is from strength to aggression, not the reverse (Petersen \& Dawes, 2017). Similarly, a possibility exists that some variables omitted from the analyses confound the strength-political violence link; for example, health may cause both, self-perceived strength and willingness to engage in political violence. However, Petersen \& Dawes (2017) suggest that the primary part of the strength-aggression association is genetic in nature: "individual differences in aggression are calibrated by heritable differences in physical formidability" (p. 165). If genetic variation substantially accounts for physical strength, which in turn calibrates propensity to aggression, then this rules out many environmental confounders of the strength-aggression association. 
Note, however, that this logic may not extent to political aggression, i.e., Petersen \& Dawes (2017) analyzed dyadic aggression.

Second, I relied on a self-perception measure of strength introduced by Sell et al. (2009). Although this measure correlates with objective measures of physical strength, such as weight lifting, the correlation is not perfect. In addition, the self-perception measure is composed of only one item; hence, it likely suffers from considerable measurement error, thereby causing imprecision in the estimates. Here, it is important to mention that Petersen \& Laustsen (2019) also found no gender difference in the association between strength and Social Dominance Orientation when using subjective measures of strength but found such differences when using objective measures.

Third, and related, the behavioral self-report of political violence was also composed of only one item; hence, it also likely suffers from considerable measurement error. The Radicalism Intention Scale (RIS), is composed of four items, and has been validated in previous research (e.g., with respect to reliability and dimensionality; see Moskalenko \& McCauley, 2009). However, to my knowledge, the measurement equivalence of RIS across different cultures has not yet been demonstrated. On the surface, the items composing RIS seem straightforward, containing such terms as "police", "violence", and "protest", which likely carrying the same meaning across different cultures. Still, in absence of formal tests of measurement invariance, a possibility exists that interviewees from different countries ascribe different meanings to these terms. ${ }^{11}$ Taken together, the

\footnotetext{
${ }^{11}$ Also note that the third item of RIS ("I would participate in a public protest against oppression of my group even if I thought the protest might turn violent") may be interpreted as referring to violence initiated by the oppressors, and not to the would-be violence by interviewees (i.e., the intended meaning).
} 
measurement issues may partly account for the small coefficient of strength, lack of significant gender differences, and the heterogeneity in the estimates across the four samples.

Fourth, although the strength-political violence association was highly significant in the pooled sample and for both outcomes, country-specific analyses revealed betweencountry variation in the coefficients and confidence intervals. Small number of countries does not allow assessing whether this between-country variation is statistically significant (vs. comes about by chance) and whether it systematically varies with some country-level characteristics. To elaborate, the between-country variation in the coefficient associated with strength, as well as the coefficients associated with the interactions, have unsystematic and systematic components. The unsystematic component refers to random noise (e.g., due to measurement error) that does not vary with any country-level characteristic. The systematic component refers to country-level characteristics that moderate the individual-level associations. For example, Sell et al. (2017) found no correlation between strength and support for war among Israeli men, in contrast to Argentinian, Romanian, and Danish men. The authors suggest that this null finding potentially reflects the fact that Israeli interviewees were more likely to have had military experience, and hence that their internal sense of fighting capacity more strongly depended on martial skills (e.g., accuracy of fire-arm shooing) than physical strength.

Similar logic may also explain some results of the present paper. For example, the association between strength and both outcome measures was weakest in Venezuela, and Venezuela was the only country among the four with mandatory military service (i.e., conscription). According to the Military Balance Database, Venezuela also had a considerably larger per 1,000 capita military personnel: 11.1, compared to 6.8 in the US, 
2 in Nicaragua, and 1.5 in South Africa (these numbers include active, reserve, and paramilitary personnel in 2019).

In addition, Venezuela experienced protests of the largest scale among the four countries. Large-scale protests, partly characterized by violence, potentially make more citizens aware of the risks involved in confronting large and better-organized government forces, and the negligible role individuals play in the overall protest success. Hence, exposure to or recent history of intra-state political violence, may also moderate the association between physical strength and willingness to participate in political violence.

However, these post hoc considerations must be treated with caution. Limited data (i.e., small $\mathrm{N}$ of countries) do not allow assessing whether military experience or exposure to political violence - or any other characteristic measured at the countrylevel - systematically moderate the individual-level association between strength and political violence. Several other patterns, however, appear clear: the association between strength and political violence is weak and likely varies across countries. Therefore, analyses of the strength-political violence association require large samples; otherwise, a considerable risk exists that scholars falsely reject the association, which-despite being weak - reliably appears in large multinational samples (see also Section S4 in the SM).

Importantly, the small coefficient of strength, lack of (or non-robust) gender differences, and between-country variation in the estimates also characterize previous research. For example, Sell et al. (2017) report the following correlations between strength and support for war among males: Argentina: $r=0.20, p=0.016$; Denmark: $r=0.11$, $p=0.012$; Israel: $r=0.02, p=0.42$; Romania: $r=0.20, p=0.04$. The slightly stronger correlations among Argentinians and Romanians potentially reflect the fact that these are undergraduate samples. As the present paper suggests, the strength-violence association is negatively moderated by age. Furthermore, Sell et al. (2017) used one-tailed 
tests. Two-tailed tests, which are more conservative, would produce significant correlations (at $5 \%$ level) in only two of their samples (i.e., Argentina and Denmark). In turn, Sell et al. (2017) also found significant differences between correlation coefficients across men and women sub-samples in only two countries (Denmark and Romanian), and twotailed test would produce significant differences in just one (Denmark). ${ }^{12}$ Taken together, the associations reported in Sell et al. (2017), just like in the present paper, are relatively weak, imprecisely estimated, and vary across countries.

Combined, these considerations point to the following design improvements in future research. Importantly, given the concerns over reverse causation and omitted variables, (i) scholars should explore designs to experimentally manipulate strength. Manipulating actual strength may be practically or ethically challenging (although, see the discussion section in Laustsen \& Petersen, 2019). By contrast, perceptions of strength could be plausibly manipulated using existing paradigms, for example, false performance feedback (e.g., Hutchinson et al. 2008). Subsequently, future research (ii) should develop new multi-item measures of self-perceived formidability, or utilize available ones (e.g., the Self-Perceived Formidability Scale by Durkee et al., 2018). In turn, scholars (iii) should develop multi-item measures of political violence and asses their measurement

\footnotetext{
12 Sell et al. (2009) also report "marginally significant" association between strength and endorsement of war (Utility of Political Aggression scale) among women ( $\mathrm{r}=0.13, \mathrm{p}=$ 0.06), although analogous correlation among men was considerably larger $(\mathrm{r}=0.23, \mathrm{p}=$ 0.005). In Supporting Information online, Sell et al. (2009) also report a controlled model, showing that the association between self- and other- perception measure of strength and endorsement of war among men is $r=0.18, p=0.10$. All tests in Sell et al. (2009) are one-tailed.
} 
invariance, particularly if used in multinational analyses. Finally, (iv) future research should use large multinational samples with larger $\mathrm{N}$ of countries. Larger $\mathrm{N}$ of countries or other higher-level units may not only be needed to detect the weak association between strength and political violence, but also to identify potential cross-level interactions in multilevel analyses. This would allow developing more nuanced theories of political violence that account for how evolved psychological adaptations interact with modern environments (for example, how modern military training calibrates the weight of physical strength in coalitional aggression-regulating mechanisms).

\subsection{New research agenda in the study of political violence}

Aside from the particular results pertaining to physical strength, this report hints at a new research agenda. The study of what makes people start or join intra-state political violence has been dominated by political science (Fearon \& Laitin, 2003) and economics (Collier \& Hoeffler, 2004). Psychologists have traditionally focused on non-violent forms of collective action and largely relied on WEIRD samples (van Zomeren et al., 2008). Only recently, political violence has attracted a more considerable attention among psychologists (e.g., Becker and Tausch, 2015). So far, this research has largely focused on established predictors of collective action in social psychology, such as group-based injustice or political efficacy. Here, I suggest expanding this research to variables that ancestrally likely predicted participation in coalitional aggression. In this report, I focused on the most obvious choice: physical strength. A range of other variables remain unexplored, for example, those pertaining to coalitional strength (Sell et al. 2016) or leader characteristics (Laustsen \& Petersen, 2017). Such an adaptationist research program in the study of political violence (Lopez \& McDermott, 2012) would not only help answering the question of whether modern political aggression follows the ancestral logic 
of small-scale coalitional aggression. It may also generate important clues about why political aggression occurs, why it assumes particular forms, and what we can do to prevent it.

\section{References}

Afrobarometer Data. (2015). Merged Round 5 Data, 34 Countries, 2011-2013 (last update: July 2015). (http://www.afrobarometer.org). (Accessed 13 January 2021)

Archer, J. \& Thanzami, V. (2007). The relation between physical aggression, size and strength, among a sample of young Indian men. Personality and Individual Differences, 43(3): 627-633.

Archer, J. \& Thanzami, V. (2009). The relation between mate value, entitlement, physical aggression, size and strength among a sample of young Indian men. Evolution and Human Behavior, 30(5): 315-321.

Bambor, T., Clark, W. R., \& Golder, M. (2006). Understanding interaction models: Improving empirical analyses: Political Analysis, 14(1): 63-82.

Bartusevičius, H., van Leeuwen, F., \& Petersen, M. B. (2020). Dominance-driven autocratic political orientations predict political violence in Western, educated, industrialized, rich, and democratic (WEIRD) and non-WEIRD samples. Psychological Science, 31(12): 1511-1530.

Becker, J. C. \& Tausch, N. (2015). A dynamic model of engagement in normative and non-normative collective action: Psychological antecedents, consequences, and barriers. European Review of Social Psychology, 26(1): 43-92.

Bell, A., Fairbrother, M., \& Jones, K. (2019). Fixed and random effect models: Making an informed choice. Quality \& Quantity, 53, 1051-1074. 
Beyerlein, K., Barwis, P., Crubaugh, B., \& Carnesecca, C. (2018). A new picture of protest: The national study of protest events. Sociological Methods $\&$ Research, 47(3): 384-429.

Collier, P. \& Hoeffler, A. (2004). Greed and grievance in civil war. Oxford Economic Papers, 56(4): 563-595.

Daly, M. \& Wilson, M. (1988). Homicide. Aldine.

Dixon, J. (2009). What causes civil wars? Integrating quantitative research findings. International Studies Review, 11(4): 707-735.

Durkee, K. P., Goetz, A. T., \& Lukaszewski, A. W. (2018). Formidability assessment mechanisms: Examining their speed and automaticity. Evolution and Human Behavior, 39(2): 170-178.

Fearon, J. D. \& Laitin, D. D. (2003). Ethnicity, insurgency, and civil war. American Political Science Review, 97(1): 75-90.

Felson, R. B. (1996). Big people hit little people: Sex differences in physical power and interpersonal violence. Criminology, 34(3): 433-452.

Fry, D. (2015) War, peace, and human nature: The convergence of evolutionary and cultural views. Oxford University Press.

Gallup, A. C., White, D. D., \& Gallup Jr, G. G. (2007). Handgrip strength predicts sexual behavior, body morphology, and aggression in male college students. Evolution and Human Behavior, 28(6): 423-429.

Ghobarah, H. A., Huth, P., \& Russett, B. (2003). Civil wars kill and maim people-long after the shooting stops. American Political Science Review, 97(2): 189-202. 
Gleditsch, K. S. (2020). Advances in data on conflict and dissent. In Computational Conflict Research, pages 23-41. Springer.

Gómez, A., López-Rodríguez, L., Sheikh, H., Ginges, J., Wilson, L., Waziri, H., Vázquez, A., Davis, R., \& Atran, S. (2017). The devoted actor's will to fight and the spiritual dimension of human conflict. Nature Human Behaviour, 1(9): 673-679.

Hainmueller, J., Mummolo, J., \& Xu, Y. (2019). How much should we trust estimates from multiplicative interaction models? Simple tools to improve empirical practice. Political Analysis, 27(2): 163-192.

Hess, N., Helfrecht, C., Hagen, E., Sell, A. \& Hewlett, B. (2010). Interpersonal aggression among Aka hunter-gatherers of the Central African Republic: Assessing the effects of sex, strength, and anger. Human Nature, 21, 330-354.

Hutchinson, J. C., Sherman, T., Martinovic, N., \& Tenenbaum, G. (2008). The effect of manipulated self-efficacy on perceived and sustained effort. Journal of Applied Sport Psychology, 20(4): 457-472.

Kishi, R. \& Jones, S. (2020) Demonstrations and political violence in America: New data for summer 2020. (https://acleddata.com/2020/09/03/demonstrations-politicalviolence-in-america-new-data-for-summer-2020/). (Accessed 13 January 2021)

Laustsen, L. \& Petersen, M. B. (2017) Perceived conflict and leader dominance: Individual and contextual factors behind preferences for dominant leaders. Political Psychology, 38(6): 1083-1107.

Petersen, M. B., \& Laustsen, L. (2019) Upper-body strength and political egalitarianism: Twelve conceptual replications. Political Psychology, 40(2): 375-394.

Lopez, A. C. \& McDermott, R. (2012). Adaptation, heritability, and the emergence of evolutionary political science. Political Psychology, 33(3): 343-362. 
McNeish, D. \& Kelley, K. (2019). Fixed effects models versus mixed effects models for clustered data: Reviewing the approaches, disentangling the differences, and making recommendations. Psychological Methods, 24(1): 20-35.

Moskalenko, S. \& McCauley, C. (2009). Measuring political mobilization: The distinction between activism and radicalism. Terrorism and Political Violence, 21(2): 239260.

Operario, D., Adler, N. E., \& Williams, D. R. (2004). Subjective social status: Reliability and predictive utility for global health. Psychology \& Health, 19(2): 237-246.

Pellegrini, A. D., Roseth, C. J., Mliner, S., Bohn, C. M., Van Ryzin, M., Vance, N., Cheatham, C. L., \& Tarullo, A. (2007). Social dominance in preschool classrooms. Journal of Comparative Psychology, 121(1): 54.

Petersen, M. B. \& Dawes, C. T. (2017). Assessing causal pathways between physical formidability and aggression in human males. Personality and Individual Differences, 113: 161-166.

Petersen, M. B., Sznycer, D., Sell, A., Cosmides, L., \& Tooby, J. (2013). The ancestral logic of politics: Upper-body strength regulates men's assertion of self-interest over economic redistribution. Psychological Science, 24(7): 1098-1103.

Pettersson, T., \& Oberg, M. (2020). Organized violence, 1989-2019. Journal of Peace Research, 56(4): 589-603.

Price, M. E., Dunn, J., Hopkins, S., \& Kang, J. (2012). Anthropometric correlates of human anger. Evolution and Human Behavior, 33(3): 174-181.

Price, M. E., Kang, J., Dunn, J., \& Hopkins, S. (2011). Muscularity and attractiveness as predictors of human egalitarianism. Personality and Individual Differences, 50(5): 636-640. 
Raine, A., Reynolds, C., Venables, P. H., Mednick, S. A., \& Farrington, D. P. (1998). Fearlessness, stimulation-seeking, and large body size at age 3 years as early predispositions to childhood aggression at age 11 years. Archives of General Psychiatry, 55(8): 745-751.

Salehyan, I., Hendrix, C. S., Hamner, J., Case, C., Linebarger, C., Stull, E., \& Williams, J. (2012). Social conflict in Africa: A new database. International Interactions, $38(4): 503-511$.

Sell, A., Eisner, M., \& Ribeaud, D. (2016). Bargaining power and adolescent aggression: The role of fighting ability, coalitional strength, and mate value. Evolution and Human Behavior, 37(2): 105-116.

Sell, A., Sznycer, D., Cosmides, L., Tooby, J., Krauss, A., Nisu, S., Ceapa, C., \& Petersen, M. B. (2017). Physically strong men are more militant: A test across four countries. Evolution and Human Behavior, 38(3): 334-340.

Sell, A., Tooby, J., \& Cosmides, L. (2009). Formidability and the logic of human anger. Proceedings of the National Academy of Sciences, 106(35): 15073-15078.

Sheeran, P. (2002). Intention-behavior relations: a conceptual and empirical review. European Review of Social Psychology, 12(1): 1-36.

Tremblay, R. E. (1998). Testosterone, physical aggression, dominance, and physical development in early adolescence. International Journal of Behavioral Development, 22(4): $753-777$.

van Zomeren, M., Postmes, T., \& Spears, R. (2008). Toward an integrative social identity model of collective action: A quantitative research synthesis of three sociopsychological perspectives. Psychological Bulletin, 134(4): 504. 
von Rueden, C., Gurven, M., \& Kaplan, H. (2008). The multiple dimensions of male social status in an Amazonian society. Evolution and Human Behavior, 29(6): 402-415. 


\section{Supplemental Material (for)}

\section{Physical strength predicts political violence}

Henrikas Bartusevičius

Contents

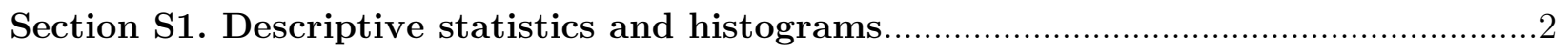

Table S1. Descriptive statistics, pooled sample ……………………........................

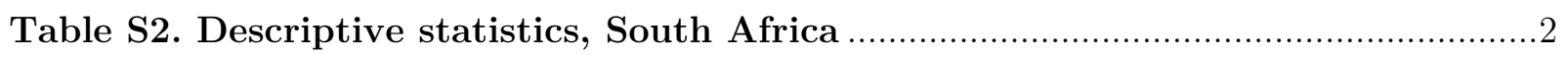

Table S3. Descriptive statistics, Venezuela …………..............................................

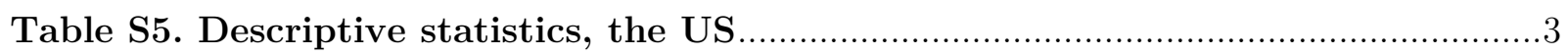

Figure S1. Histograms of self-reported participation in political violence ....................4

Figure S2. Histograms of Radicalism Intention Scale (RIS) .....................................

Figure S3. Histograms of self-perceived strength.................................................. 6

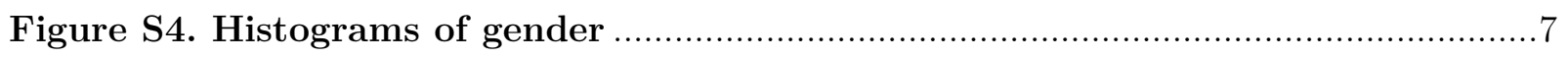

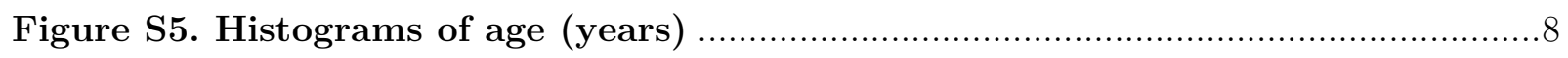

Figure S6. Histograms of age (categories, from 18-22 to 80+) ……..........................

Figure S7. Histograms of education ..................................................................... 10

Figure S8. Histograms of Subjective Social Status Scale ……………………..........11

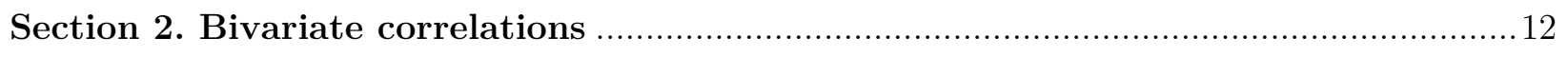

Table S6. Bivariate correlation matrix, pooled sample ...............................................12

Table S7. Bivariate correlation matrix, South Africa ………………………….......... 12

Table S8. Bivariate correlation matrix, Venezuela …………………………….........13

Table S9. Bivariate correlation matrix, Nicaragua …………………………............13

Table S10. Bivariate correlation matrix, the US ……………..................................

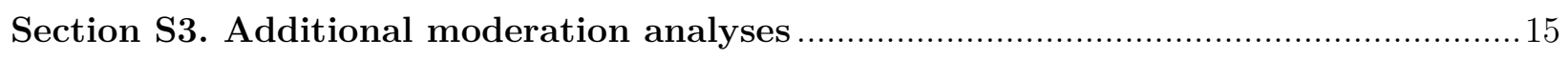

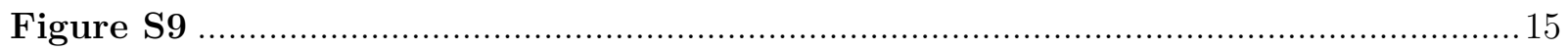

Figure S10 …

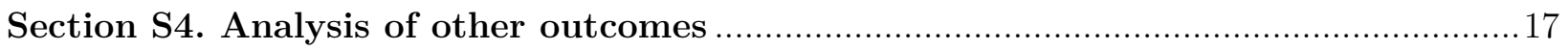




\section{Section S1. Descriptive statistics and histograms}

Table S1. Descriptive statistics, pooled sample

\begin{tabular}{lcccccc}
\hline & $\mathrm{N}$ & Mean & Median & SD & Min & Max \\
\hline Self-reported participation in political violence & 6012 & 0.20 & 0.00 & 0.62 & 0 & 4 \\
Radicalism Intention Scale (RIS) & 5994 & 1.48 & 1.00 & 1.64 & 0 & 6 \\
Self-perceived strength & 5185 & 47.21 & 50.00 & 25.91 & 0 & 100 \\
Gender & 6216 & 0.52 & 1.00 & 0.50 & 0 & 1 \\
Age & 4542 & 35.75 & 32.00 & 13.73 & 18 & 90 \\
Age categories & 6081 & 4.71 & 4.00 & 3.09 & 1 & 13 \\
Education & 6189 & 1.97 & 2.00 & 0.98 & 0 & 3 \\
Subjective Social Status Scale & 5704 & 5.34 & 5.00 & 1.99 & 1 & 10 \\
\hline
\end{tabular}

Table S2. Descriptive statistics, South Africa

\begin{tabular}{lcccccc}
\hline & $\mathrm{N}$ & Mean & Median & SD & Min & Max \\
\hline Self-reported participation in political violence & 2069 & 0.14 & 0.00 & 0.52 & 0 & 4 \\
Radicalism Intention Scale (RIS) & 2060 & 1.31 & 0.75 & 1.55 & 0 & 6 \\
Self-perceived strength & 1763 & 52.53 & 50.00 & 24.69 & 0 & 100 \\
Gender & 2127 & 0.46 & 0.00 & 0.50 & 0 & 1 \\
Age & 2132 & 40.11 & 37.00 & 15.27 & 18 & 82 \\
Age categories & 2132 & 5.02 & 4.00 & 3.05 & 1 & 13 \\
Education & 2097 & 1.60 & 1.00 & 0.96 & 0 & 3 \\
Subjective Social Status Scale & 1843 & 5.35 & 5.00 & 1.94 & 1 & 10 \\
\hline
\end{tabular}

Table S3. Descriptive statistics, Venezuela

\begin{tabular}{lcccccc}
\hline & $\mathrm{N}$ & Mean & Median & SD & Min & Max \\
\hline Self-reported participation in political violence & 980 & 0.30 & 0.00 & 0.65 & 0 & 4 \\
Radicalism Intention Scale (RIS) & 984 & 1.91 & 1.50 & 1.72 & 0 & 6 \\
Self-perceived strength & 864 & 47.18 & 50.00 & 25.19 & 0 & 100 \\
Gender & 1000 & 0.52 & 1.00 & 0.50 & 0 & 1 \\
Age & 965 & 36.09 & 34.00 & 12.47 & 18 & 77 \\
Age categories & 965 & 4.21 & 4.00 & 2.50 & 1 & 12 \\
Education & 999 & 2.50 & 3.00 & 0.79 & 0 & 3 \\
Subjective Social Status Scale & 983 & 6.15 & 6.00 & 1.76 & 1 & 10 \\
\hline
\end{tabular}


Table S4. Descriptive statistics, Nicaragua

\begin{tabular}{lcccccc}
\hline & $\mathrm{N}$ & Mean & Median & SD & Min & Max \\
\hline Self-reported participation in political violence & 1504 & 0.13 & 0.00 & 0.46 & 0 & 4 \\
Radicalism Intention Scale (RIS) & 1475 & 1.33 & 0.50 & 1.66 & 0 & 6 \\
Self-perceived strength & 1261 & 39.30 & 40.00 & 27.07 & 0 & 100 \\
Gender & 1550 & 0.63 & 1.00 & 0.48 & 0 & 1 \\
Age & 1445 & 29.07 & 27.00 & 8.50 & 18 & 90 \\
Age categories & 1445 & 2.82 & 2.00 & 1.72 & 1 & 13 \\
Education & 1554 & 2.20 & 2.00 & 0.87 & 0 & 3 \\
Subjective Social Status Scale & 1467 & 4.63 & 5.00 & 1.89 & 1 & 10 \\
\hline
\end{tabular}

Table S5. Descriptive statistics, the US

\begin{tabular}{lcccccc}
\hline & $\mathrm{N}$ & Mean & Median & SD & Min & Max \\
\hline Self-reported participation in political violence & 1459 & 0.29 & 0.00 & 0.83 & 0 & 4 \\
Radicalism Intention Scale (RIS) & 1475 & 1.59 & 1.25 & 1.64 & 0 & 6 \\
Self-perceived strength & 1297 & 47.67 & 50.00 & 24.96 & 0 & 100 \\
Gender & 1539 & 0.48 & 0.00 & 0.50 & 0 & 1 \\
Age & - & - & - & - & - & - \\
Age categories & 1539 & 6.37 & 6.00 & 3.43 & 1 & 13 \\
Education & 1539 & 1.91 & 2.00 & 0.99 & 0 & 3 \\
Subjective Social Status Scale & 1411 & 5.49 & 6.00 & 2.05 & 1 & 10 \\
\hline
\end{tabular}


Figure S1. Histograms of self-reported participation in political violence

Figure S2. Histograms of Radicalism Intention Scale (RIS)
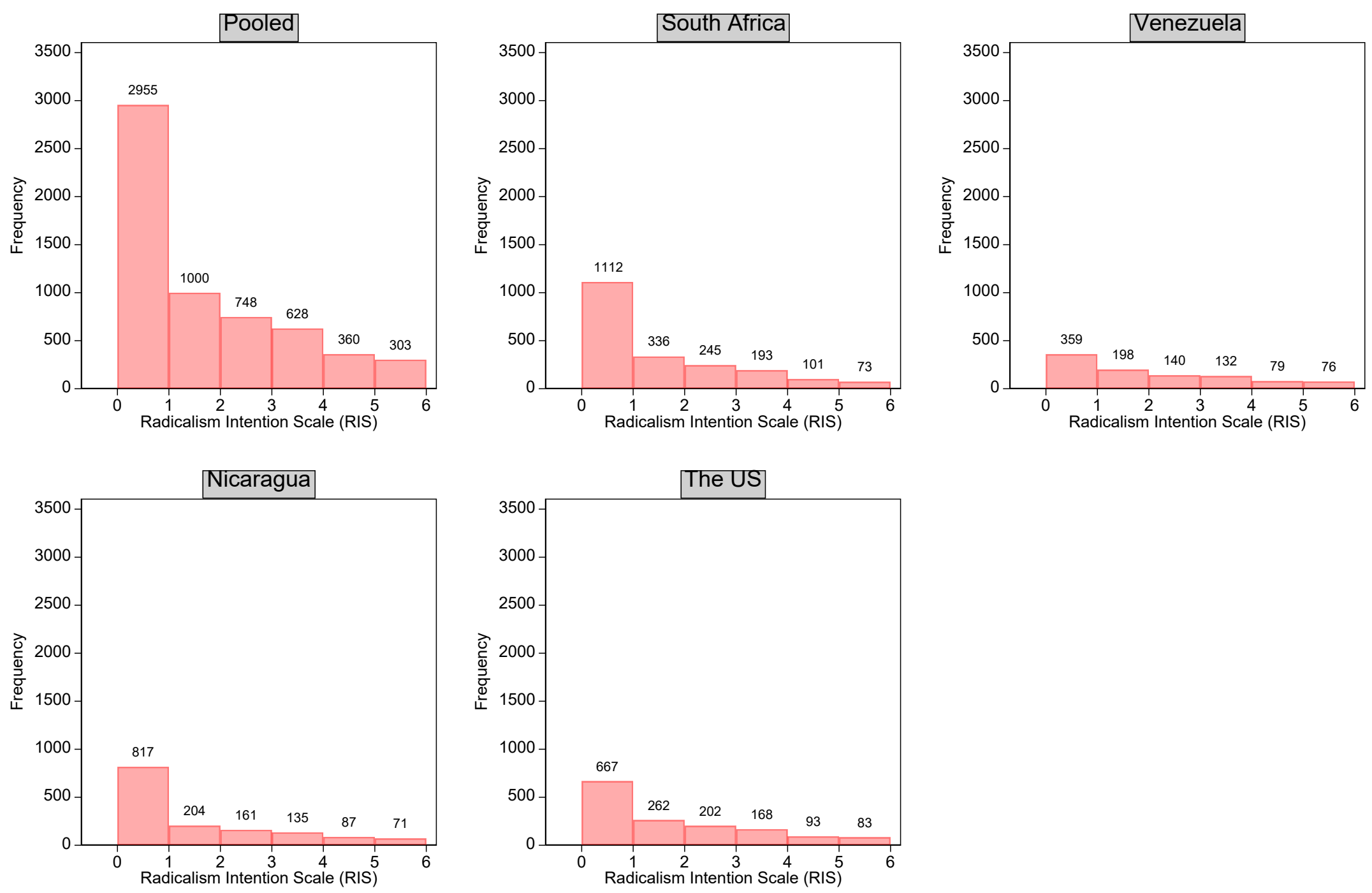
Figure S3. Histograms of self-perceived strength
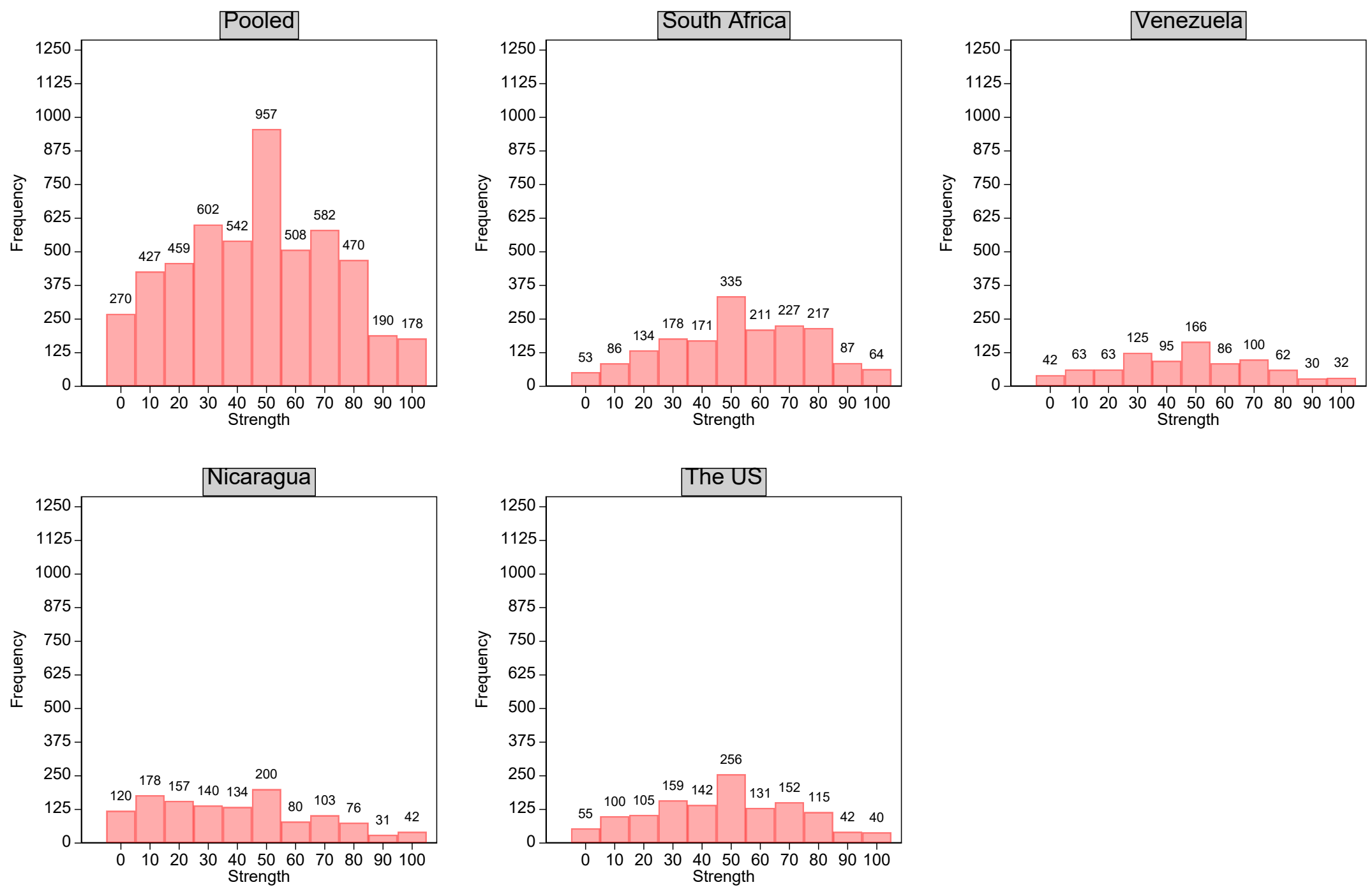
Figure S4. Histograms of gender
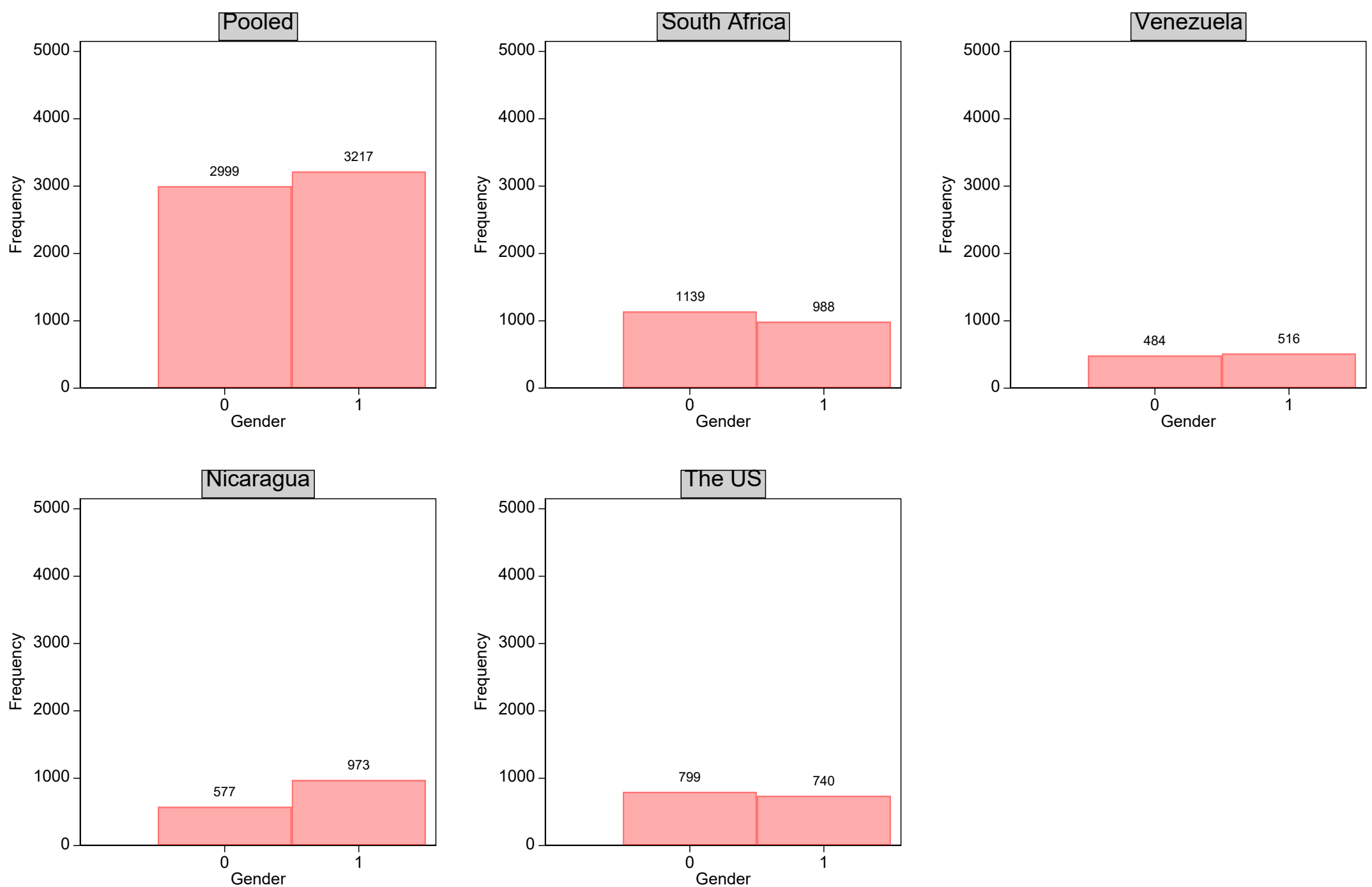
Figure S5. Histograms of age (years)
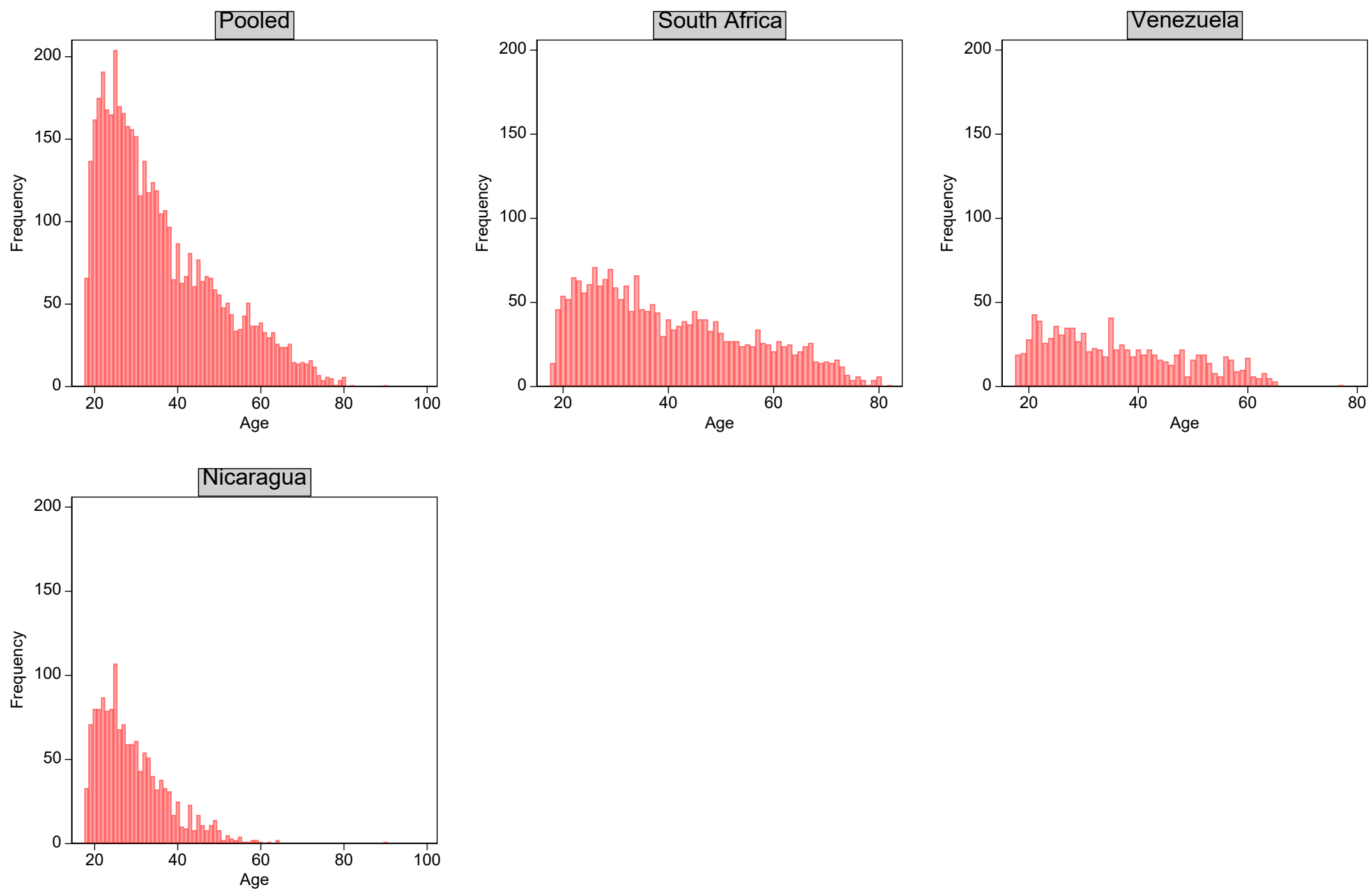
Figure S6. Histograms of age (categories, from 18-22 to $80+$ )
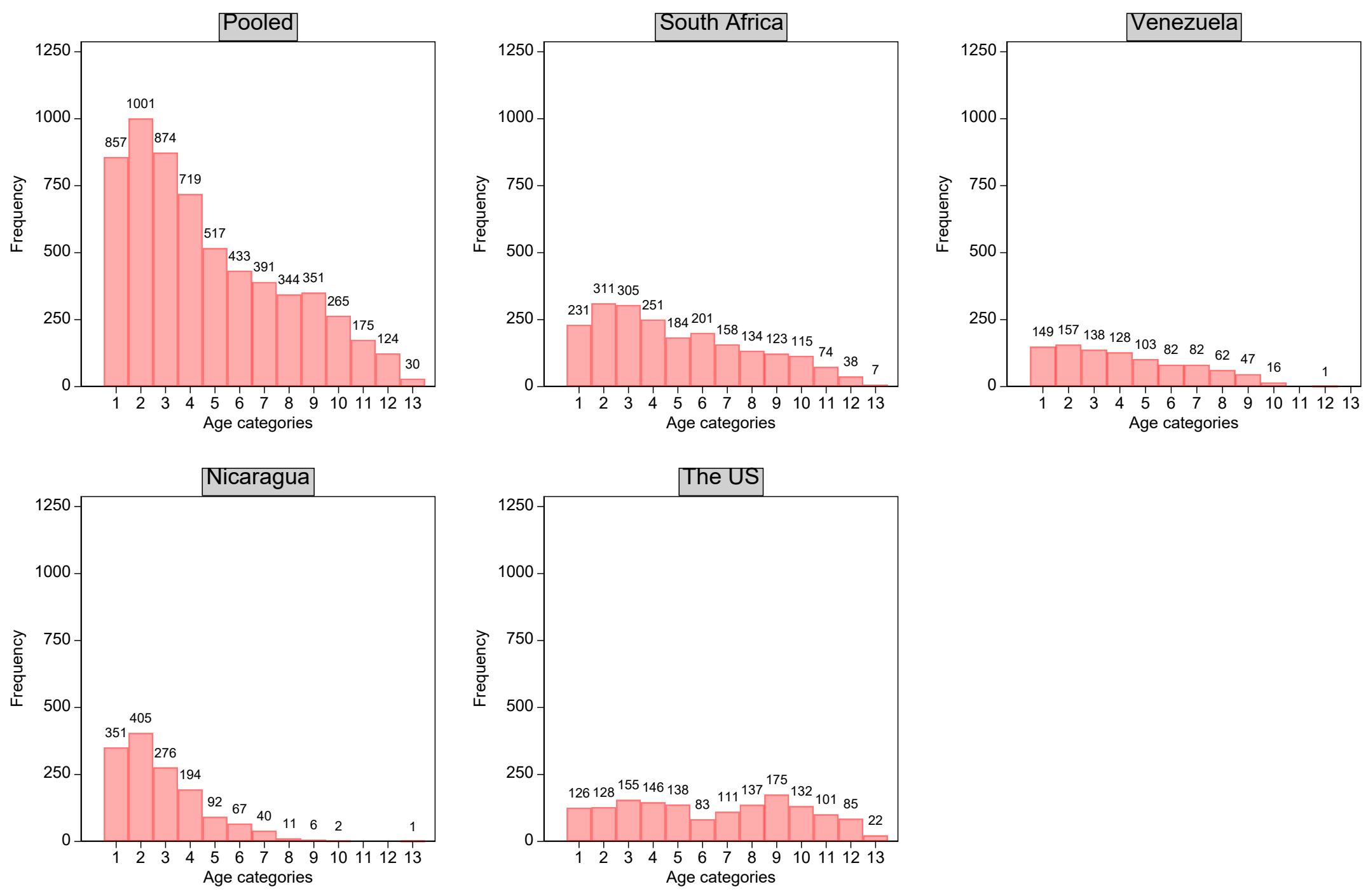
Figure S7. Histograms of education
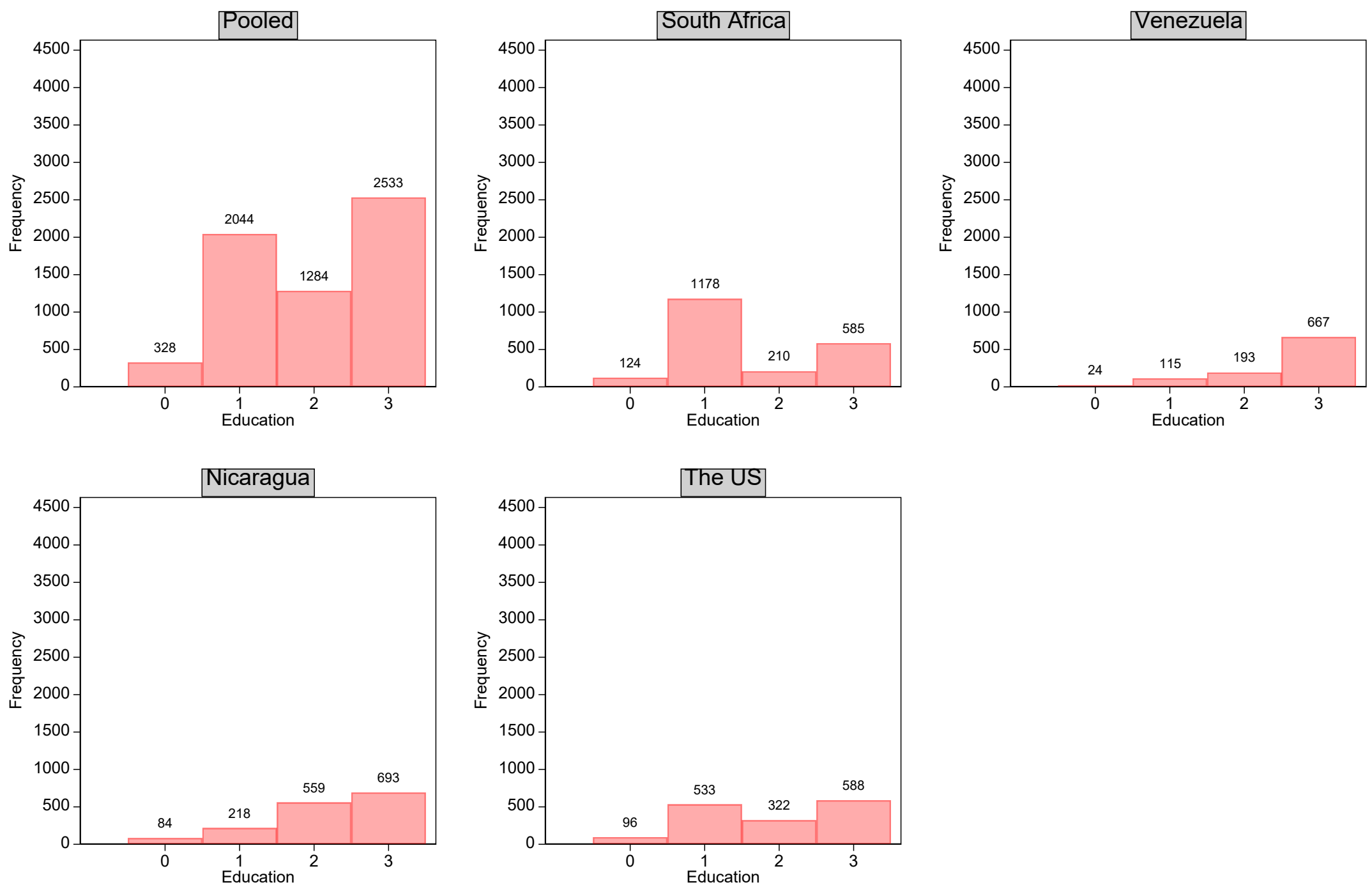
Figure S8. Histograms of Subjective Social Status Scale
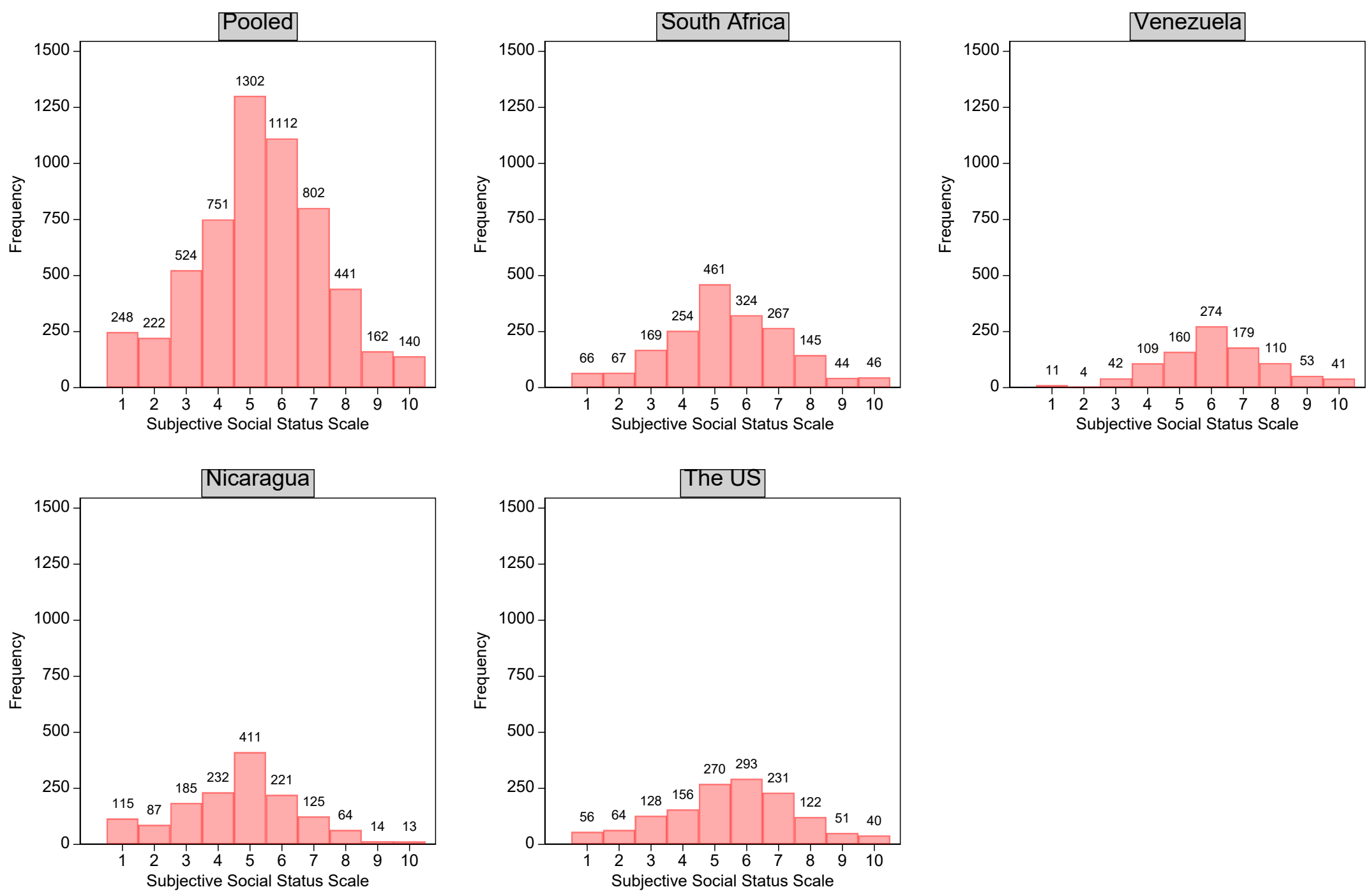


\section{Section 2. Bivariate correlations}

Table S6. Bivariate correlation matrix, pooled sample

\begin{tabular}{|c|c|c|c|c|c|c|c|c|}
\hline & $(1)$ & $(2)$ & $(3)$ & $(4)$ & $(5)$ & (6) & $(7)$ & $(8)$ \\
\hline (1) Self-reported participation in political violence & 1.000 & & & & & & & \\
\hline (2) Radicalism Intention Scale (RIS) & 0.454 & 1.000 & & & & & & \\
\hline (3) Self-perceived strength & 0.058 & 0.044 & 1.000 & & & & & \\
\hline (4) Gender & 0.070 & 0.105 & -0.018 & 1.000 & & & & \\
\hline (5) Age & -0.058 & -0.121 & 0.073 & -0.014 & 1.000 & & & \\
\hline (6) Age categories & -0.118 & -0.169 & 0.058 & -0.018 & 0.995 & 1.000 & & \\
\hline (7) Education & 0.034 & 0.064 & 0.023 & 0.023 & -0.059 & -0.062 & 1.000 & \\
\hline (8) Subjective Social Status Scale & 0.083 & 0.055 & 0.148 & 0.020 & 0.084 & 0.085 & 0.165 & 1.000 \\
\hline
\end{tabular}

\section{Table S7. Bivariate correlation matrix, South Africa}

\begin{tabular}{|c|c|c|c|c|c|c|c|c|}
\hline & $(1)$ & $(2)$ & $(3)$ & $(4)$ & $(5)$ & $(6)$ & $(7)$ & $(8)$ \\
\hline (1) Self-reported participation in political violence & 1.000 & & & & & & & \\
\hline (2) Radicalism Intention Scale (RIS) & 0.427 & 1.000 & & & & & & \\
\hline (3) Self-perceived strength & 0.073 & 0.092 & 1.000 & & & & & \\
\hline (4) Gender & 0.075 & 0.138 & 0.005 & 1.000 & & & & \\
\hline (5) Age & -0.114 & -0.200 & -0.080 & 0.064 & 1.000 & & & \\
\hline (6) Age categories & -0.110 & -0.197 & -0.080 & 0.064 & 0.996 & 1.000 & & \\
\hline (7) Education & 0.083 & 0.109 & 0.042 & 0.090 & -0.076 & -0.080 & 1.000 & \\
\hline (8) Subjective Social Status Scale & 0.086 & 0.090 & 0.178 & 0.056 & 0.054 & 0.051 & 0.234 & 1.000 \\
\hline
\end{tabular}


Table S8. Bivariate correlation matrix, Venezuela

\begin{tabular}{cccccccc}
$(1)$ & $(2)$ & $(3)$ & $(4)$ & $(5)$ & $(6)$ & $(7)$ & $(8)$ \\
1.000 & & & & & & & \\
0.498 & 1.000 & & & & & & \\
0.036 & 0.002 & 1.000 & & & & & \\
0.094 & 0.119 & -0.023 & 1.000 & & & & \\
-0.052 & -0.032 & 0.073 & 0.040 & 1.000 & & & \\
-0.048 & -0.034 & 0.072 & 0.039 & 0.994 & 1.000 & & \\
-0.035 & -0.000 & 0.112 & -0.084 & 0.226 & 0.229 & 1.000 & \\
-0.026 & -0.066 & -0.133 & 0.030 & -0.037 & -0.039 & -0.091 & 1.000 \\
\hline & & & & & & &
\end{tabular}

Table S9. Bivariate correlation matrix, Nicaragua

(1) Self-reported participation in political violence 1.000

(2) Radicalism Intention Scale (RIS)

(3) Self-perceived strength

(4) Gender

(5) Age

(6) Age categories

(7) Education

(8) Subjective Social Status Scale

(1) (2)

(3)

$(4)$

$(5)$

(6)

$(7)$

$(8)$

\begin{tabular}{cccccccc}
0.321 & 1.000 & & & & & & \\
0.054 & 0.037 & 1.000 & & & & & \\
0.044 & 0.042 & 0.047 & 1.000 & & & & \\
0.031 & -0.076 & 0.097 & -0.019 & 1.000 & & & \\
0.037 & -0.071 & 0.095 & -0.017 & 0.986 & 1.000 & & \\
-0.027 & -0.032 & 0.102 & -0.124 & 0.224 & 0.201 & 1.000 & \\
0.003 & 0.000 & 0.152 & -0.048 & 0.022 & 0.031 & 0.162 & 1.000 \\
\hline
\end{tabular}


Table S10. Bivariate correlation matrix, the US

\begin{tabular}{lcccccc}
\hline & $(1)$ & $(2)$ & $(3)$ & $(4)$ & $(5)$ & $(6)$ \\
\hline (1) Self-reported participation in political violence & 1.000 & & & & & \\
(2) Radicalism Intention Scale (RIS) & 0.540 & 1.000 & & & & \\
(3) Self-perceived strength & 0.061 & 0.035 & 1.000 & & \\
(4) Gender & 0.091 & 0.130 & -0.010 & 1.000 & & \\
(6) Age categories & -0.310 & -0.365 & 0.028 & 0.013 & 1.000 & \\
(7) Education & 0.008 & 0.023 & 0.062 & 0.009 & -0.030 & 1.000 \\
(8) Subjective Social Status Scale & 0.121 & 0.045 & 0.204 & 0.118 & 0.059 & 0.201 \\
\hline
\end{tabular}




\section{Section S3. Additional moderation analyses}

\section{Figure S9. Additional moderation analyses: Self-reported participation in political violence}
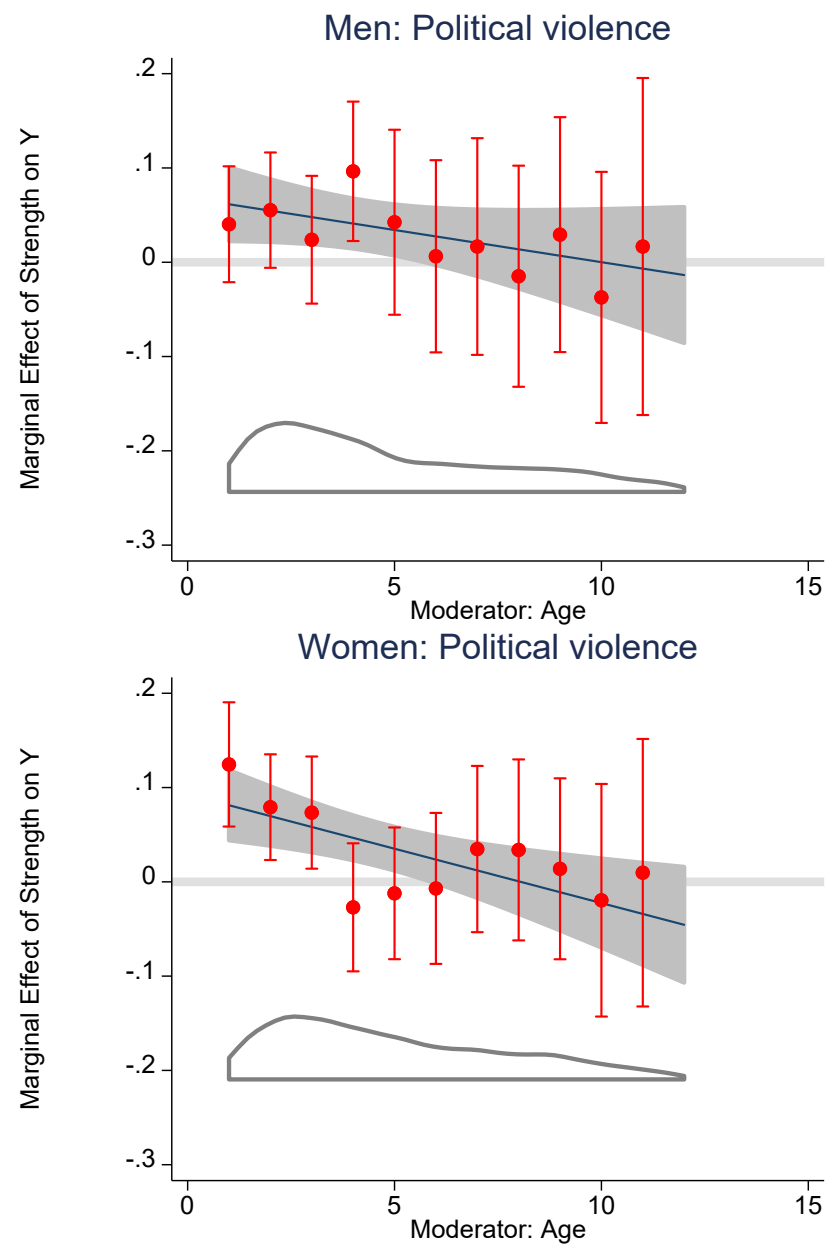

Note: Marginal effects of strength on self-reported participation in political violence among men and women for different age categories. The graphs depict estimates of the marginal effects of strength with 95\% CIs from the binning estimator (represented by dots with vertical bars), superimposed by estimates of the marginal effects of strength with $95 \%$ CIs from the standard linear interaction model (diagonal lines with shaded areas). Lower parts of graphs represent age density. 
Figure S10. Additional moderation analyses: Radicalism Intention Scale (RIS)
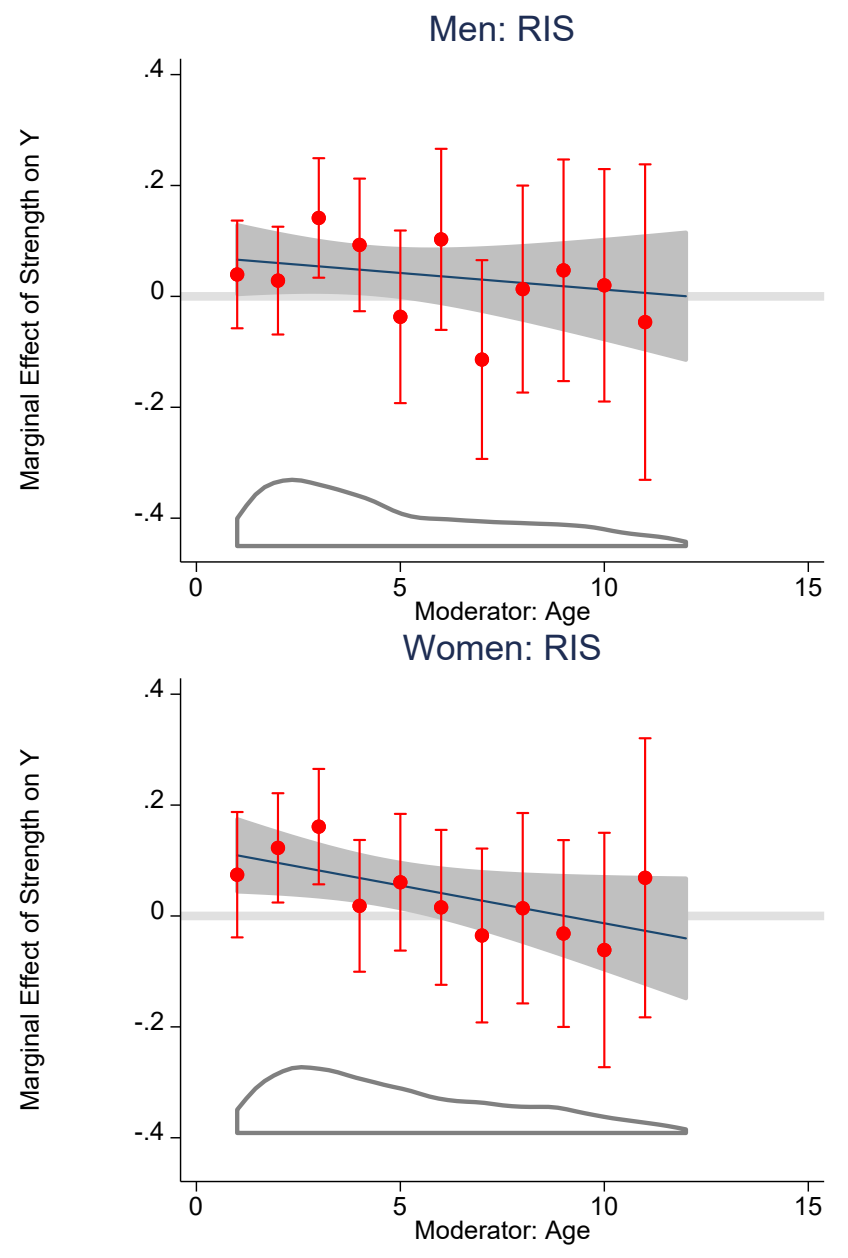

Note: Marginal effects of strength on behavioral intentions to participate in political violence (indexed with the Radicalism Intention Scale, RIS) among men and women for different age categories. The graphs depict estimates of the marginal effects of strength with $95 \%$ CIs from the binning estimator (represented by dots with vertical bars), superimposed by estimates of the marginal effects of strength with $95 \%$ CIs from the standard linear interaction model (diagonal lines with shaded areas). Lower parts of graphs represent age density. 


\section{Section S4. Analysis of other outcomes}

The South African survey, in addition to the outcomes reported in the main text, also measured trait aggression with the 3-item Physical Aggression sub-scale from the Brief Aggression Questionnaire (Webster et al. 2014) (e.g., "Given enough provocation, I may hit another person"; reply options ranged from extremely uncharacteristic of me to extremely characteristic of me; Cronbach's $\alpha=.81$ ). Estimated in a bivariate OLS regression model, the association between strength and trait aggression was $b=0.058,95 \% \mathrm{CI}=[0.002,0.114]$ $(\mathrm{p}=0.043)$. All tests here and below are two-tailed, and all predictors and outcomes are $0-$ 1 normalized. The strength-gender multiplicative interaction was $b=0.009,95 \% \mathrm{CI}=[-$ $0.101,0.118](\mathrm{p}=0.874)$. The strength-age interaction was $b=-0.161,95 \% \mathrm{CI}=[-0.386$, $0.064](\mathrm{p}=0.160)$.

The Venezuela survey also measured trait aggression with the same 3-item Physical Aggression subscale $(\alpha=.81)$. The association between strength and trait aggression was $b$ $=0.016,95 \% \mathrm{CI}=[-0.055,0.086](\mathrm{p}=0.663)$. The strength-gender interaction was $b=$ $0.076,95 \% \mathrm{CI}=[-0.060,0.211](\mathrm{p}=0.272)$. The strength-age interaction was $b=-0.299$, $95 \% \mathrm{CI}=[-0.619,0.021](\mathrm{p}=0.067)$.

The Venezuela survey also obtained several measures of attitudinal support for political violence. During the survey, Venezuela experienced food shortages. The questionnaire included vignettes describing a situation of conflict between a hypothetical newly elected government and opposition, during which the government destroyed food supplies sent by an aid organization. The interviewees were asked to indicate agreement with "It is justifiable to use violence against people who take food away from those who need it" on a 7-point scale, ranging from strongly disagree to strongly agree. The association between strength 
and support for violence against the hypothetical government was $b=-0.019,95 \% \mathrm{CI}=[-$ $0.120, .081](\mathrm{p}=0.707)$. The strength-gender interaction was $b=0.174,95 \% \mathrm{CI}=[-0.027$, 0.374] $(\mathrm{p}=0.089)$. The strength-age interaction was $b=-0.242,95 \% \mathrm{CI}=[-0.702,0.218]$ $(\mathrm{p}=0.303)$.

The survey also measured general militancy with a 5-item scale, adapted from the Militant Extremism Mind-Set scale by Stankov et al. (2010): 1) "I would retaliate against members of a group that had attacked my group"; 2) "I would go to war to protect my group"; 3) "Killing is justified when it is an act of revenge"; 4) "The only way to teach a lesson to our enemies is to threaten their lives and make them suffer"; and 5) "War is the beginning of salvation". Interviewees indicated agreement with the five items on a 7-point scale, ranging from strongly disagree to strongly agree $(\alpha=.76)$. The association between strength and militancy was $b=0.076,95 \% \mathrm{CI}=[0.020,0.133](\mathrm{p}=0.009)$. The strength-gender interaction was $b=0.033,95 \% \mathrm{CI}=[-0.080,0.145](\mathrm{p}=0.569)$. The strength-age interaction was $b=-0.150,95 \% \mathrm{CI}=[-0.409,0.109](\mathrm{p}=0.225)$.

We also obtained a 3-item scale measuring general support for political violence: 1) "The use of violence is never justified, not even to protect my human rights"; 2) "In Venezuela, it is sometimes necessary to use political violence in support of a just cause"; 3) "Under some conditions, war is necessary to obtain justice". Interviewees indicated agreement with the three items on a 7-point scale, ranging from strongly disagree to strongly agree. The scale had low reliability, $\alpha=.50$. The association between strength and general support for political violence was $b=-0.020,95 \% \mathrm{CI}=[-0.093,0.054](\mathrm{p}=0.604)$. The strength-gender interaction was $b=0.060,95 \% \mathrm{CI}=[-0.087,0.207](\mathrm{p}=0.424)$. The strength-age interaction was $b=0.013,95 \% \mathrm{CI}=[-0.326,0.351](\mathrm{p}=0.941)$. 
The questionnaire contained another vignette, describing a conflict between a hypothetical newly elected government/president and opposition, during which a protester was killed by police. The interviewees were asked to indicate willingness to respond to the killing in four ways: 1) "Tell a friend that it is justified to use violence to oppose the new president"; 2) "Help members of a violent political movement that opposes the new president"; 3) "Join a violent political movement that opposes the new president"; 4) "Use force or violence as part of fighting the new president". Interviewees indicated likelihood on a 7-point scale, ranging from would never do this to would certainly do this $(\alpha=.94)$. The association between strength and intentions to engage in violence against the hypothetical president/government was $b=0.056,95 \% \mathrm{CI}=[-.017,0.129](\mathrm{p}=0.131)$. The strength-gender interaction was $b=0.144,95 \% \mathrm{CI}=[-0.001,0.289](\mathrm{p}=0.051)$. The strength-age interaction was $b=0.151,95 \% \mathrm{CI}=[-0.183,0.485](\mathrm{p}=0.375)$.

The Nicaragua survey also measured trait aggression with the same 3-item Physical Aggression subscale $(\alpha=.84)$. The association between strength and trait aggression was $b$ $=0.125,95 \% \mathrm{CI}=[0.067,0.183](\mathrm{p}<0.001)$. The strength-gender interaction was $b=$ $0.037,95 \% \mathrm{CI}=[-0.083,0.158](\mathrm{p}=0.541)$. The strength-age interaction was $b=-0.227$, $95 \% \mathrm{CI}=[-0.630,0.176](\mathrm{p}=0.270)$.

The questionnaire also contained a vignette analogous to that in the Venezuela survey, describing a conflict between a hypothetical newly elected government/president and opposition, during which a protester was killed by police. The association between strength and intentions to engage in violence against the hypothetical president/government was $b=$ $0.040,95 \% \mathrm{CI}=[-0.003, .082](\mathrm{p}=0.067)$. The strength-gender interaction was $b=-0.040$, $95 \% \mathrm{CI}=[-0.129,0.049](\mathrm{p}=0.378)$. The strength-age interaction was $b=-0.101,95 \% \mathrm{CI}$ $=[-0.396,0.194](\mathrm{p}=0.503)$. 
The Nicaragua survey contained another vignette, describing a hypothetical newly elected government/president, which deliberates punishing vs. forgiving the previous government that perpetrated human rights violations. The interviewees were asked to indicate intentions to engage in violence against the hypothetical government/president: 1) "I would tell a friend that it is justified to use violence against the government"; 2) "I would help members of a violent political movement that opposes the government"; 3) "I would join a violent political movement that opposes the government"; 4) "I would use force or violence as part of fighting the government". Interviewees indicated agreement with the four items on a 7 point scale, ranging from strongly disagree to strongly agree $(\alpha=.88)$. The association between strength and intentions to engage in violence against the hypothetical government/president was $b=0.033,95 \% \mathrm{CI}=[-0.010,0.076](\mathrm{p}=0.131)$. The strength-gender interaction was $b=-0.037,95 \% \mathrm{CI}=[-0.127,0.053](\mathrm{p}=0.423)$. The strength-age interaction was $b=-0.093,95 \% \mathrm{CI}=[-0.389,0.204](\mathrm{p}=0.540)$.

The US survey only obtained the two measures of political violence as reported in the main text.

In summary, the results reported above are consistent with the estimates reported in the main text. Some coefficients reported here are above conventional statistical significance thresholds. However, these insignificant estimates are generated by single-country analyses, and as discussed in the main text, the association between strength and political aggression is weak, and hence may only be detected in the larger pooled sample. For example, as reported above, strength significantly predicted trait aggression in South Africa $(b=0.058$, $95 \% \mathrm{CI}=[0.002,0.114], \mathrm{p}=0.043)$ and Nicaragua $(b=0.125,95 \% \mathrm{CI}=[0.067,0.183], \mathrm{p}$ $<0.001)$, but not in Venezuela $(b=0.016,95 \% \mathrm{CI}=[-0.055,0.086], \mathrm{p}=0.663)$ (trait aggression was not measured in the US). However, in the pooled three-country sample, the coefficient of strength was highly significant $b=0.073,95 \% \mathrm{CI}=[0.038,0.108], \mathrm{p}<0.001)$. 
Similarly, the strength-age interaction in the model of trait aggression was insignificant in all three countries (South Africa: $b=-0.161,95 \% \mathrm{CI}=[-0.386,0.064], \mathrm{p}=0.160$; Venezuela: $b=-0.299,95 \% \mathrm{CI}=[-0.619,0.021], \mathrm{p}=0.067$; and Nicaragua: $b=-0.227,95 \% \mathrm{CI}=[-$ $0.630,0.176], \mathrm{p}=0.270$ ), but highly significant in the pooled sample, $b=-0.249,95 \% \mathrm{CI}=$ $[-0.407,-0.091], \mathrm{p}=0.002)$. Note that these analyses include country-level fixed effects, and hence use only within-country variation in strength and political violence to estimate the coefficients. In this way, all country-level confounders (i.e., country-level variables that account for between-country variation), are controlled for.

Likewise, the association between strength and intentions to engage in violence against the hypothetical government responsible for the killing of the protester was insignificant in the Venezuela $(b=0.056,95 \% \mathrm{CI}=[-.017,0.129], \mathrm{p}=0.131)$ and Nicaragua $(b=0.040,95 \%$ $\mathrm{CI}=[-0.003, .082], \mathrm{p}=0.067$ ) (this outcome was not measured in South Africa and the US), but significant in the pooled two-country sample, $b=0.046,95 \% \mathrm{CI}=[0.007,0.084]$, $(\mathrm{p}=0.020)$. By contrast, the strength-age interaction in this model remained insignificant in the two-country pooled sample, $b=0.049,95 \% \mathrm{CI}=[-0.160,0.257], \mathrm{p}=0.647$.

All other outcomes (i.e., general support for political violence, militancy, as well as intentions to engage in political violence/support for political violence measured following other experimental vignettes) were only measured in single countries, and hence their associations with strength in multinational samples cannot be estimated.

All four surveys measured a number of other variables unrelated to political violence. All original questionnaires are publicly available on the Open Science Framework (OSF): https://osf.io/y8gfk/. 